\title{
Chitosan-sodium alginate-fatty acid nanocarrier composite: lutein bioavailability, absorption pharmacokinetics in diabetic rat and protection of retinal cells against $\mathrm{H}_{2} \mathrm{O}_{2}$ induced oxidative stress in vitro
}

\author{
Veeresh B Toragall \\ CFTRI, Mysore \\ Baskarn V ( $\square$ baskaranv@cftri.res.in ) \\ CFTRI, Mysore
}

\section{Research Article}

Keywords: Lutein, nanocarrier composite, bioavailability, pharmacokinetics, mitochondrial membrane potential, cellular uptake

Posted Date: August 2nd, 2020

DOl: https://doi.org/10.21203/rs.3.rs-51890/v1

License: @ (i) This work is licensed under a Creative Commons Attribution 4.0 International License. Read Full License 


\section{Abstract}

Aiming to enhance therapeutic efficiency of lutein, lutein loaded chitosan-sodium alginate (CS-SA) based nanocarrier composite (LNCs) were prepared and evaluated for lutein bioavailability and pharmacokinetics in diabetic rats in comparison to micellar lutein (control). Further, cytotoxicity, cellular uptake and protective activity against $\mathrm{H}_{2} \mathrm{O}_{2}$ induced oxidative stress in ARPE-19 cells were studied. Results revealed that LNCs displayed maximal lutein AUC in plasma, liver and eye respectively in normal (3.1, 2.7 and 5.2 folds) and diabetic (7.3, 3.4 and 2.8 folds) rats. Lutein from LNCs exhibited a higher half-life time, mean residence time and slow clearance from the plasma, indicating prolonged circulation compared to control. In ARPE-19 cells, pre-treatment with LNCs $(10 \mu \mathrm{M})$ have significantly attenuated $\mathrm{H}_{2} \mathrm{O}_{2}$ induced cell death, intracellular ROS and mitochondrial membrane potential compared to control. In conclusion, LNCs improve the lutein bioavailability in conditions like diabetes, diabetic retinopathy and cataract to curtail oxidative stress in retinal cells.

\section{Introduction}

Lutein ( $\beta, \varepsilon$-carotene-3,3'-diol; $\mathrm{C} 40 \mathrm{H} 5602)$, referred as macular pigment, supports visual functions owing to its antioxidant, antiinflammatory and anti-angiogenic properties. Lutein plays a vital role in ameliorating age-related macular degeneration, cataract (ocular complications) and diabetes mediated retinopathy due to radical scavenging property (Bernstein et al., 2016; Hemalatha, Naveen, \& Baskaran, 2019; Sharavana \& Baskaran, 2017). Henceforth, lutein has gained prominence in food and pharma application in treating eye- related complications (J. Chang et al., 2018; Rafi, Kanakasabai, Gokarn, Krueger, \& Bright, 2015; Wu et al., 2015). Unfortunately, human cannot synthesize lutein de nova and hence has to be acquired through dietary sources or supplements. Moreover, lutein being mostly matrixed with food factors impedes bioavailability (Lienau et al., 2003). Therefore, to meet the daily requirement of lutein, the Joint FAO/WHO Expert Committee on Food Additives (Joint, Additives, \& Organization, 2005) revised the recommendation of daily lutein intake from $2-6 \mathrm{mg} / \mathrm{Kg}$ body weight to $6-12 \mathrm{mg} / \mathrm{kg}$ body weight. Though, it has been reported that the effective dose of lutein essential to prevent ocular complications is much higher than the value recommended by JECFA (Frede et al., 2014). Consequently, various commercial lutein formulations have emerged in the market to tackle its food security. Besides, studies have shown that lutein bioavailability is poor owning to its hydrophobic nature, lower aqueous solubility, stability, sensitive to light, heat and oxygen tension because of unsaturated bonds (Boon, McClements, Weiss, \& Decker, 2010; Kotake-Nara \& Nagao, 2011). These constraints limit lutein application in the food and pharma industries. Since the level of daily dietary intake of lutein falls short to achieve benefits, approaches to upsurge lutein bioavailability and distribution to target tissues could yield higher health benefits.

To achieve an efficient lutein bioavailability, target delivery and efficacy to fight against macular degeneration, cataract and retinopathy require newer strategies. Many techniques have been emerged to enhance the stability, solubility and bioavailability of lutein. Among several techniques, nanotechnology is currently used effectively in food, cosmetic and pharmaceutical applications with newer biodegradable polymeric carriers along with suitable lipids to enhance pharmacokinetics and biological activity of lipophilic molecule lutein (Kumari, Yadav, \& Yadav, 2010; Ranganathan, Hindupur, \& Vallikannan, 2016). Previously, we have reported that low molecular weight chitosan and PLGA (Poly Lactic-co- Glycolic Acid) nanocarriers system enhanced lutein and fucoxanthin bioavailability in mice (Arunkumar, Prashanth, \& Baskaran, 2013; Ranganathan et al., 2016; Ravi \& Baskaran, 2015). We have also reported characteristic features and the safety of chitosan-alginate-oleic acid-based nanocarrier system (Toragall, Jayapala, \& Vallikannan, 2020).

Previously, we have reported an inclusion of oleic acid (OL) in micelles and nano preparation improved intestinal absorption of $\beta$ carotene, lutein and fucoxanthin and their levels in plasma and tissue including retina (Mamatha \& Baskaran, 2011; Ranganathan et al., 2016; Sugawara et al., 2001). Polymer and lipid-based carriers are two major bioactives and drug delivery systems that are widely used across the food and pharma industries (Ravi \& Baskaran, 2015; Vishwanathan, Wilson, \& Nicolosi, 2009). These delivery systems have their own leads and drawbacks. Hence, in the present study, we have designed a lutein loaded nanocarrier system (LNCs) using natural polymers chitosan (CS) and sodium alginate (SA) to protect lutein from the acidic $\mathrm{pH}$ of the stomach and intestine. OL was added to the LNCs to provide a lipid core and to enhance the lutein solubility and bioavailability. The 
prepared LNCs are expected to display superior encapsulation efficiency, stability, solubility, bioavailability, bioefficacy and sustained systemic circulation of lutein.

Based on the available literature and our previous findings, we have hypothesized that LNCs designed in the present study would enhance the intestinal absorption, pharmacokinetics and bioavailability of lutein. The objective of the study was to (1) examine the effect of LNCs on lutein bioavailability (plasma and retina response) and pharmacokinetics in control and diabetic rats and (2) to find out protective effect against $\mathrm{H} 2 \mathrm{O} 2$ induced oxidative stress in ARPE-19 cells compared to physiologically relevant vehicle (lutein mixed micelles).

\section{Materials And Methods}

\section{Materials}

Standard lutein (96\%), chitosan and oleic acid were purchased from Himedia (Mumbai, India), sodium alginate was obtained from Sigma Aldrich (Banglore, India). Low-density lipoproteins (LDL) and high-density lipoproteins (HDL) were purchased from Agape Diagnostics (Ernakulam, India). HPLC and analytical grade solvents methanol, acetonitrile, dichloromethane, acetone, sodium sulfate, potassium hydroxide, ammonium acetate, and other chemicals were purchased from Sisco Research Laboratory (Mumbai, India).

\section{Structural characteristics of polymers chitosan (CS) and sodium alginate (SA)}

Characteristics of CS (degree of deacetylation $\geq 75 \%$ and viscosity $348 \mathrm{cP}$ ) was measured at $1 \% \mathrm{CS}(\mathrm{w} / \mathrm{V})$ in the water at $25^{\circ} \mathrm{C}$, $100 \mathrm{rpm}$ and $34.8 \%$ torque using the spindle number 3, Brookfield viscometer, RV DV-II+Pro, USA and the intrinsic viscosity [ $\mathrm{n}$ ] was calculated as per Chattopadhyay \& Inamdar (2010). Based on intrinsic viscosity, average molecular weight (Mw $213 \mathrm{kDa}, 1 \% \mathrm{w} / \mathrm{v}$ solution) of chitosan was calculated using the Mark-Houwink equation $[\eta]=K$ Ma, where, $\mathrm{K}=3.5 \times 10-4$ and $\mathrm{a}=0.76(1 \% \mathrm{w} / \mathrm{v}$, in $0.5 \%$ acetic acid solution (Kumar \& KV, 2019).

Characteristics of SA (viscosity $175 \mathrm{cP}$ ) was measured at $1 \% \mathrm{SA}(\mathrm{w} / \mathrm{v})$ in the water at $25^{\circ} \mathrm{C}, 100 \mathrm{rpm}$ and $17.5 \%$ torque using the spindle number 1 (Brookfield viscometer, RV DV-II+Pro, USA), FTIR spectroscopy (Bruker, Tensor II, Germany) was used quantify the mannuronate/guluronate (M/G) ratio (1.84) of SA (Chandıa, Matsuhiro, \& Vásquez, 2001; Dodero, Vicini, Alloisio, \& Castellano, 2019; Filippov \& Kohn, 1974) in particular, correlating absorption band at $808 \mathrm{~cm}-1$ assigned to $M$ units and $787 \mathrm{~cm}-1$ to $\mathrm{G}$ units. The interaction of chitosan-sodium alginate polymer composite is given in Figure 1.

\section{Purification of lutein}

Lutein was extracted and purified from fresh marigold (Tagetes erecta) flower petals with ice-cold acetone containing $0.1 \%$ butyl hydroxyl toluene for experimental use. In brief, the acetone extract was filtered over anhydrous sodium sulfate to remove moisture and saponified with $30 \%$ methanolic potassium hydroxide in the dark for $3 \mathrm{~h}$ at room temperature $\left(27 \pm 2{ }^{\circ} \mathrm{C}\right)$ and phase separated with distilled water. The carotenoids rich hexane phase was collected, pooled, concentrated, and loaded onto an activated silica column (60-120 mesh). A mixture of dichloromethane: methanol $(1: 1, v / v)$ was used to elute lutein and its purity was confirmed by high-performance liquid chromatography (HPLC) and liquid chromatography- mass spectrometry (LC-MS) (Lakshminarayana, Raju, Prakash, \& Baskaran, 2009; Toragall, Jayapala, \& Vallikannan, 2020).

\section{Preparation of nanocarrier system by ionic gelation method}

The lutein loaded nanocarrier (LNCs) system was prepared by the ionotropic gelation method (Farshid \& Lakshmi, 2017) with modification (Toragall, Jayapala, \& Vallikannan, 2020). In brief, chitosan ( $1 \mathrm{mg} / \mathrm{mL}$ ) was dissolved in $0.1 \%$ acetic acid solution. Purified lutein was mixed with oleic acid at $1: 2$ ratio with $0.1 \%$ tween 80 and added to the chitosan solution in a dropwise manner under continuous stirring at 800 rpm using a magnetic stirrer (REMI CM-101 plus, India) for 30 min. Sodium alginate solution (0.5 $\mathrm{mg} / \mathrm{mL}$ ) was added to the mixture and stirred for $30 \mathrm{~min}$ and the mixture was sonicated for $15 \mathrm{~min}$ (probe sonicator, PCl, Mumbai, 
India) at $50 \mathrm{~Hz}$ on the ice followed by high-speed homogenization (ULTRA-TURRAX-T25, IKA, USA) at $15000 \mathrm{rpm}$ for $10 \mathrm{~min}$ that resulted in LNCs.

\section{Particle size and zeta potential of LNCs}

Dynamic light scattering (DLS) was used to determine the hydrodynamic size of LNCs. The LNCs was diluted ( 10 fold) with triple distilled water to avoid the multiple scattering phenomena results from the concentrated sample and subjected to analysis. The particle size, zeta potential and polydispersity index (PDI) of LNCs were examined by zetasizer (Nano-ZS 90, Malvern Instruments Ltd, Worcestershire, UK). Measurements were made in triplicates at $90^{\circ}$ scattering angle at a temperature of $25^{\circ} \mathrm{C}$.

\section{Shape and morphology of LNCS}

The surface and surface morphology of LNCs were analyzed by scanning electron microscopy (SEM) (ZEISS EVO, Thornwood, USA) operated at a voltage of 5-15kV. In brief, a drop (2-5 $\mathrm{LL})$ of nanosuspension or a small quantity of spray-dried powder (0.1$0.2 \mathrm{mg}$ ) was mounted on a circular metal SEM stub with a double-sided sticky tape, air-dried at room temperature. Air-dried samples were sputter coated with gold and allowed to dry at room temperature and observed under SEM in secondary electron imaging mode (Sadiq et al., 2016). The shape and size of LNCs were confirmed by transmission electron microscopy (TEM) examination (Titan Themis $300 \mathrm{kV}$ from FEl, Thermo Scientific ${ }^{\mathrm{TM}}$. Waltham, Massachusetts, USA). In brief, an aqueous nanosuspension sample of LNCs was deposited upon a carbon-coated copper grid and air-dried for $1 \mathrm{~min}$. Then, the sample was instantly stained with $2 \%$ phosphotungstic acid, randomly scanned and photomicrographs were taken at different magnification.

\section{Lutein encapsulation efficiency}

The encapsulation efficiency (EE) of lutein was determined by centrifuging nanosuspension $(1 \mathrm{~mL})$ at $14000 \mathrm{rpm}$ for $20 \mathrm{~min}$ at 4 ${ }^{\circ} \mathrm{C}$ (Eppendorf, 5810R, Germany). The concentration of unencapsulated lutein was extracted and measured by using HPLC in comparison with standard lutein (Lakshminarayana, Raju, Krishnakantha, \& Baskaran, 2006). EE was calculated as per the formula given below:

\section{Lutein EE $(\%)=\frac{\mathrm{IL}-\mathrm{LS}}{\mathrm{IL}} * 100$}

where, IL is initial lutein concentration, LS is lutein concentration in the supernatant.

\section{Lutein- mixed micelles preparation}

Mixed micelles were prepared as per (Lakshminarayana et al., 2006). In brief, monooleoyl glycerol (2.5 mM), oleic acid (7.5 mM), sodium taurocholate $(12 \mathrm{mM})$ and lutein $(600 \mu \mathrm{M})$ were dissolved in methanol separately and mixed to reach the final concentration. The solvent was evaporated using nitrogen gas, and the mixture was resuspended in phosphate buffer saline $(\mathrm{pH}$ 7.4) with sonication (PCl, Mumbai, India) for 30 min to obtain mixed micelles. Lutein concentration in the mixed micelles and LNCs was confirmed by HPLC before using for cell culture and animal studies.

\section{Pharmacokinetic study}

\section{Animals}

The animal experiment was carried out after due clearance from the CFTRI animal ethics committee (FT/AHF/Al/129/2019). Pharmacokinetic studies were carried out on healthy male Wistar rats (age, 6-8 weeks), weighing $150 \pm 10 \mathrm{~g}$, which were housed individually in polypropylene cages. Animals were maintained in an environmentally controlled atmospheric condition at $28 \pm 2{ }^{\circ} \mathrm{C}$ with $12 \mathrm{~h}$ light: dark cycle and given free access to feed (Champaka feeds and foods, Bengaluru, India) and water at CFTRI animals house facility.

\section{Diabetes induction}

Page $4 / 21$ 
For diabetes induction, a single dose of STZ (38 mg/kg body weight) was injected intraperitoneal to the overnight fasted $(n=20)$ rats. Rats were given free access to feed and water. Prior to STZ injection, rats were acclimatised for 1 week and fasting blood glucose was examined (Sharavana \& Baskaran, 2017). Rats with $>200 \mathrm{mg} / \mathrm{dL}$ blood glucose concentration were considered as diabetic rats (Sharavana \& Baskaran, 2017).

\section{Dosing}

Micellar (control) and LNCs lutein concentration was determined as per (Toragall, Jayapala, \& Vallikannan, 2020). In brief, 1mL of LNCs or mixed micelles was extracted for lutein and confirmed the purity by HPLC prior to intubation to animals. Lutein concentration in LNCs was determined based on the encapsulation efficiency. Rats were gavaged $(0.2 \mathrm{~mL})$ lutein $(600 \mu \mathrm{M})$ either in mixed micelles or LNCs.

\section{Bioavailability of lutein from $L N C S$}

Rat $(n=40)$ were divided into two groups as control $(n=20)$ and diabetic $(n=20)$ and were fasted overnight with free access to water. Rats in each group was divided into 2 sub-groups ( $n=10 /$ group) and gavaged $600 \mu \mathrm{M}$ lutein $(0.5 \mathrm{~mL})$ either mixed micelles (control) or LNCs. Blood $(200 \mu \mathrm{L})$ was collected at different time points $(2,4,8,12$ and $16 \mathrm{~h})$ of post-dose through the retro-orbital route from three animals into $1.5 \mathrm{~mL}$ eppendorf tube coated with heparin (Table 1). Plasma was collected by centrifugation (Eppendorf, 5810R, Germany) at $2900 \mathrm{rpm}$ at $4^{\circ} \mathrm{C}$ for $10 \mathrm{~min}$ and organs were harvested, snap-frozen and stored at $-80^{\circ} \mathrm{C}$ until analysis.

Table 1.Experimental design adopted for the pharmacokinetic study

\begin{tabular}{|c|c|c|c|c|}
\hline Groups & Sub-groups & No. animals & Lutein dose & $\begin{array}{c}\text { Blood collection } \\
\text { intervals (h) }\end{array}$ \\
\hline Control & Mixed micelles & 10 & \multirow{2}{*}{$600 \mu \mathrm{M}$} & \multirow{2}{*}{$0,2,4,8,12,16$} \\
\cline { 2 - 3 } & LNCs & 10 & & \\
\hline Diabetic & Mixed micelles & 10 & & \\
\cline { 2 - 3 } & LNCs & 10 & & \\
\hline
\end{tabular}

Cell culture, maintenance and cell viability assay

Human retinal pigment epithelial (ARPE-19) cell line was procured from the American Type Culture Collection (ATCC $\AA^{\mathrm{C}} \mathrm{CRL}-2302^{\mathrm{TM}}$ ) (Manassas, Virginia, USA) and was maintained in Dulbecco's Modified Eagle Medium: Nutrient Mixture F-12 (DMEM/F12) with $10 \%$ heat-inactivated FBS, penicillin $(100 \mathrm{U} / \mathrm{mL})$ and streptomycin $(100 \mu \mathrm{g} / \mathrm{mL})$. Cells were maintained at $37^{\circ} \mathrm{C}$ in a humidified atmosphere with $5 \% \mathrm{CO}$. The percent viability was measured by MTT assay (3-(4, 5-dimethylthiazol-2-yl)-2, 5-diphenyl tetrazolium bromide). Briefly, cells were seeded into 96 well plates at $2 \times 104$ cells per well and were treated with either micellar lutein or lutein $(0,1,5,10,15,15,20$ and $50 \mu \mathrm{M})$ loaded NCs for $24 \mathrm{~h}$. Control cells received fresh medium and vehicle control received LNCs without lutein were compared with LNCs treatment groups. Each well was then added with $10 \mu \mathrm{L}$ MTT and incubated for $3 \mathrm{~h}$ at $37^{\circ} \mathrm{C}$, media was removed, and DMSO $(150 \mu \mathrm{L})$ was added to solubilize the MTT formazan and read at 520 nm using a multimode microplate reader (Infinite-M200 PRO, Tecan, Switzerland).

\section{Cellular lutein uptake}

To examine the cellular lutein uptake, ARPE-19 cells $(3 \times 106$ cells $/ \mathrm{mL})$ in $60 \mathrm{~mm} 2$ cell culture dishes were treated with either micellar lutein or LNCs for different time interval $(0,3,6,12,18,24 \mathrm{~h})$ in normal condition (without any stress) and under $\mathrm{H} 2 \mathrm{O} 2$ $(150 \mu \mathrm{M}$ for $2 \mathrm{~h}$ ) induced oxidative stress condition as evidenced in diabetes in cells and processed for lutein extraction and analysed by HPLC (Lakshminarayana et , 2009; Toragall, Jayapala, \& Vallikannan, 2020).

\section{Measurement of intracellular ROS}


Oxidative stress, result of undue generation of ROS and the subdual of ROS by antioxidant defense system, is associated with the development of retinopathy in diabetes. Hence, intracellular ROS level in the $\mathrm{H} 2 \mathrm{O} 2$ treated cells exposed to either micellar lutein or LNCs was quantified using the rate of conversion of DCFH-DA to fluorescent DCF (Driver, Kodavanti, \& Mundy, 2000). In brief, after the treatment, cells were washed twice with 1X PBS, incubated with $10 \mu \mathrm{M}$ of DCFH-DA for $30 \mathrm{~min}$ at $37^{\circ} \mathrm{C}$ in dark, washed three times with $1 \mathrm{X}$ PBS, re-suspended and PBS $(0.5 \mathrm{~mL})$ was added to each well and images were acquired using the inverted fluorescent microscope (Model 1X73, Olympus Corp., Japan). The intensity of fluorescence was analysed by Image J software. The data were expressed in percentage fluorescence relative to the control cells.

\section{Mitochondrial Membrane Potential Assay (DYm)}

In disease/disorder, mitochondrial damage in retinal pigment epithelium is initiate for the degeneration of RPE. To test this, mitochondrial membrane potential of RPE cells treated with LNCs or mixed micelles was measured by JC-1 (5,5ל,6,6 $\mathbf{c}$ -

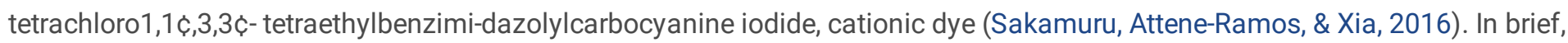
ARPE-19 cells at $2 \times 106$ cells $/ \mathrm{mL}$ in $60-\mathrm{mm} 2$ plates were grown up to $80 \%$ confluency and treated with either micellar lutein or LNCs $(10 \mu \mathrm{M})$ along with polymer control. After $24 \mathrm{~h}$, cells were treated with $\mathrm{H} 2 \mathrm{O} 2(150 \mu \mathrm{M})$ for $2 \mathrm{~h}$ and cells were harvested, washed, and stained with $10 \mathrm{mM} \mathrm{JC}-1$ at $37^{\circ} \mathrm{C}$ for $15 \mathrm{~min}$ in the dark. At a relatively high

DYm, JC-1 dye showed clump and yielded red fluorescence, whereas at a low DYm, JC-1 confined in the cytoplasm in green fluorescence. Signals were quantified by measuring red fluorescence (excitation $560 \mathrm{~nm}$, emission $595 \mathrm{~nm}$ ) and green fluorescence (excitation $485 \mathrm{~nm}$, emission $535 \mathrm{~nm}$ ) using an Infinite M200 PRO Multimode Microplate reader. Mitochondrial membrane potential (DYm) was calculated as the ratio of $\mathrm{JC}-1 \mathrm{red} / \mathrm{green}$ fluorescence intensity and values were normalised to control group. The fluorescent signal in the cells was also observed and recorded with an inverted fluorescent microscope (Model 1X73, Olympus Corp., Japan). The fluorescent signal in the ARPE-19 cells was also observed and recorded with a fluorescent microscope.

\section{Quantitation of lutein from plasma/RPE cells}

Lutein was extracted from plasma or ARPE-19 cells as per Laxshminarayana et al. (Lakshminarayana et al., 2006; Toragall, Jayapala, Muthukumar, \& Baskaran, 2020). In brief, to the plasma $(0.1 \mathrm{~mL})$, or cells $(1 \mathrm{~mL}$ homogenate) DCM:MeOH $(3 \mathrm{~mL}, 2: 1$, $v / v)$ with $2 \mathrm{mM}$ tocopherol and hexane $(1.5 \mathrm{~mL})$ was added, the mixture was vortexed and centrifuged at $3000 \mathrm{rpm}$ at $4{ }^{\circ} \mathrm{C}$ for 6 min. Lutein released in the upper phase was collected and repeated extraction for 3 times. Extracts were pooled, evaporated to dryness using the nitrogen gas and dissolved in reconstituted $50 \mu \mathrm{L}$ mobile phase (ACN:DCM:MeOH, 60:20:20 V/V/V) containing 0.1\% ammonium acetate. HPLC (LC-10A vp; Shimadzu, Kyoto, Japan), equipped with photodiode array detector (SPD-M20A), separated on Phenomenex RP-18 (ODS) column ( $250 \mathrm{~mm}$ x $4.6 \mathrm{~m} ; 5 \mu \mathrm{m})$ isocractically $(1 \mathrm{~mL} / \mathrm{min}$ flow rate) eluted with the mobile phase and detected at $450 \mathrm{~nm}$ (Shimadzu Class-VP version 6.14 SP1 software) and further, confirmed by LC-MS analysis (Lakshminarayana et al., 2009; Toragall, Jayapala, \& Vallikannan, 2020).

\section{Statistical analysis}

The data are represented as $\pm S D(n=3)$. Significance between groups interpreted by one way ANOVA with Post Tukeys test with $p \leq 0.05$ is considered as significantly different using graph pad Prism (v. 5.0). The absorption kinetics was calculated with noncompartmental analysis online software of Pharma Consulting Company, PKMP software (v. 1.03.017) and AUC with trapezoid rule with linear interpolation.

\section{Results And Discussion}

\section{Purity of lutein}

The lutein extracted from marigold flower petals found to be $\geq 96 \%$ pure, confirmed by HPLC and HRMS (Supplementary Fig. 1). The purified lutein was used for the preparation of lutein mixed micelles and LNCs. 
The DLS characterized LNCs found to have a mean particle size of $98 \pm 5 \mathrm{~nm}$ and polydispersibility index of $0.27 \pm 0.01$ (Fig. $2 \mathrm{~A} \&$ 1F), which is comparatively lesser than earlier report (Ranganathan et al., 2019). Ranganathan et al. (2019) have reported lutein nanocarrier with synthetic polymer PLGA (+PL-phospholipid) with a larger particle size of $140 \pm 6 \mathrm{~nm}$. Another interesting study by $\mathrm{H}$. Feng et al. (2017) reported that lutein loaded emulsions prepared using corn fiber gums also showed larger particle size 160$200 \mathrm{~nm}$ with lower -5.86 to $-10.6 \mathrm{mV}$ zeta potential. Similarly, Ma, Yuan, Yang, Wang, and Lv (2020) reported that lutein encapsulated zein/tea saponin composite nanoparticles displayed the larger particle size 117.9-231.1 nm. Also, Jiao et al. (2018) reported that lutein encapsulated zein-derived peptides as nanocarriers showed more massive particle (297.7 - $400 \mathrm{~nm})$ than the present findings with natural polymers (CS and SA). Further, the smaller size of LNCs established in the current study may be due to the ionic gelation method adopted for the preparation (Fig.1).

Smaller particle size and surface charge govern the stability, pharmacokinetics and bio- distribution of lutein in the body. Though the ocular barrier controls the exchange of hydrophobic molecules between the blood and ocular tissues, the size of chitosanbased NCs being less than $100 \mathrm{~nm}$, found to have higher ocular biodistribution without disturbing the integrity of the epithelial cells (Mohammed, Syeda, Wasan, \& Wasan, 2017). In addition, since the size of the LNCs was $98 \mathrm{~nm}$, it was found to easily cross the physiological (intestinal barrier and blood-retinal barrier) barriers. This could be due to the higher interfacial area of smaller particle size of LNCs, which led to maximum absorption of lutein with slow and controlled release compared to bulk materials and mixed micelles (Niamprem, Rujivipat, \& Tiyaboonchai, 2014; Ranganathan et al., 2019). This could be the possible reason for the higher plasma and RPE levels of lutein from LNCs than the micellar lutein.

Zeta potential of nanoparticle represents the surface charge (Ridolfo, Williams, \& van Hest, 2020). Higher the zeta potential (positive or negative) specifies more excellent stability of nanoparticles in the suspension with lower aggregation due to strong repellent forces existent on the surface (Vonarbourg et al., 2009). Tween 80 added in the LNCs preparation has also spiked up the steric stability (Wissing, Kayser, \& Müller, 2004). The zeta potential of LNCs was $38 \pm 4 \mathrm{mV}$, signifying the higher stability and homogeneousity of LNCs in aqueous solution. Positively charged LNCs have the advantages in targeted drug delivery due to the negatively charged electrostatic properties of the cell surface (Chen et al., 2016; Du et al., 2018). Since the glycoproteins of the intestinal mucosa are negatively charged and the designed LNCs are positively charged, mucoadhesion of LNCs can be obtained, thus facilitating the permeation of LNCs through the intestinal barrier. Similarly, LNCs can be crossed over the retinal barrier (Honary \& Zahir, 2013). This could be the reason for higher levels of lutein in the plasma and RPE-19 cells indicating higher bioavailability and cellular uptake of lutein from LNCs than from mixed micelles.

\section{Scanning electron microscopy and Transmission electron microscopy of LNCS}

The surface morphology of nanoparticles plays a crucial role in drug delivery/release (Mukerjee \& Vishwanatha, 2009). SEM micrographs of LNCs showed a discrete distribution of cluster free particles with divergent spherical shape (Fig. 2D \& 2E). LNCs are smooth surface with less than $100 \mathrm{~nm}$ size (Fig. 2F) as compared to PLGA (+PL) nanoparticle that are clustered in nature with spherical in shape and $200 \mathrm{~nm}$ size (Ranganathan et al., 2019). The size and surface morphology were further confirmed by TEM (Fig. 2B \& 2C). Therefore, smooth morphology and smaller particle size may be the reason for higher plasma and cellular levels of lutein from LNCs compared to mixed micelles (Fig. 3). However, the average particle size perceived by TEM was significantly smaller than that of DLS detection, which was due to mainly the hydration status or hydrodynamic size. At the same time, the TEM samples were dried before the examination. Acevedo Fani et al. (2017) also found that droplet sizes examined under TEM were in good agreement with those obtained by DLS. Besides, TEM reflected the local particle size of the LNCs. In contrast, DLS reflected the average particle size of LNCs, but the particle size distribution of DLS (Fig. 2E) has very good agreement with TEM results.

\section{Pharmacokinetic/bioavailability of lutein from LNCs in rats}

The postprandial plasma, liver and eye lutein responses after a single dose $(600 \mu \mathrm{M})$ of micellar lutein (control) and LNCs in normal rats are shown in Fig. 3A, 3B and 3C. Detectable level of lutein in the plasma was at $2 \mathrm{~h}$ of post-oral administration of micellar lutein. The time for absorption maxima (Tmax) was at $4 \mathrm{~h}$ with area under curve (AUC) value of $1995.1 \pm 39 \mathrm{ng} / \mathrm{mL} / 16 \mathrm{~h}$ and concentration maxima (Cmax) of $67.66 \pm 6.8 \mathrm{ng} / \mathrm{mL}$ at Tmax (Table 2). Despite the same Tmax (4 h), the Cmax (182.85 \pm $16.5 \mathrm{ng} / \mathrm{mL})$ and AUC $(1158.5 \pm 43 \mathrm{ng} / \mathrm{mL} / 16 \mathrm{~h})$ of lutein from LNCs found to be higher by 2.7 and 3.10 folds $(\mathrm{P} \leq 0.05)$

Page $7 / 21$ 
compared to control. Results show a detectable level of circulating lutein in the LNCs fed group even after $16 \mathrm{~h}$ displaying a slow and controlled release property of polymer (CS-SA) with oleic acid nanocomplex which is an important characteristics of nanocarriers (Mukerjee \& Vishwanatha, 2009). In addition, a greater (half lifetime) T1/2 (3.62 $\pm 0.2 \mathrm{~h}$ ), mean residence time (MRT) $(17.64 \pm 2.0 \mathrm{~h})$ and slower clearance $(\mathrm{Cl})(0.0054 \pm 0.001 \mathrm{ng} /(\mathrm{ng} / \mathrm{mL}) / \mathrm{h})$ from the plasma were evident in the LNCs group indicating a prolonged circulation of lutein rather than rapid clearance (Li \& Huang, 2008). These results further add to the slow and sustainable release of lutein from LNCs compared to the mixed micelles. Seto, Ueno, Suzuki, Sato, and Onoue (2019) reported that a relatively high dose of lutein nanocrystal $(230 \mathrm{~nm})$ formulation $(300 \mathrm{mg} / \mathrm{kg})$ was orally administered to the healthy rats showed poor absorption of lutein was observed based on the pharmacokinetic profiles (Cmax $11.3 \pm 2.2 \mathrm{ng} / \mathrm{mL}$ and AUC $146 \pm 24$ $\mathrm{ng} / \mathrm{mL}$ ) and decreased accumulation of lutein in the retinal tissue $(11.5 \mathrm{ng} / \mathrm{g})$. In contrast, the present study results revealed the higher LNCs lutein pharmacokinetic profile (Cmax $-67.66 \pm 6.8 \mathrm{ng} / \mathrm{mL}$ and AUC-1158.5 $\pm 43 \mathrm{ng} / \mathrm{mL}$ ) and greater tissue accumulation of lutein in the retinal tissue $(39.84 \pm 6.4 \mathrm{ng} / \mathrm{mL})$ might be due to the smaller particle size (98 nm; Fig. 2) and higher aqueous solubility of prepared LNCs. Moreover, the inadequate dissolution behavior of crystalline lutein may be one of the causes of the poor oral absorption of lutein. Regarding oral absorption mechanisms of administered lutein, enhancement in the lymphatic transport of lutein had been observed after oral administration of solid dispersion and self-micro emulsifying system (Sato et al., 2018). In this context, the part of orally administered LNCs might have been transferred into the lymph stream from the small intestine and lymphatic transport may contribute to a gradual increase in the plasma lutein concentration after oral administration of LNCs. Further, Zhao et al. (2018) have reported that lutein-cyclodextrin multiple-component delivery system orally gavaged to healthy rats at the higher dose of $3 \mathrm{mg}$ lutein (about $10 \mathrm{mg} / \mathrm{kg}$ ) displayed the Cmax of $135.8 \pm 49.7 \mathrm{ng} / \mathrm{mL}$ and AUC 633.0 \pm 209.7 $\mathrm{ng} . \mathrm{h} / \mathrm{mL}$ at Tmax of $2 \mathrm{~h}$. In contrast, LNCs prepared in the present study showed higher Cmax $(182.85 \pm 16.5 \mathrm{ng} / \mathrm{mL})$ and AUC $(1158.5 \pm 43 \mathrm{ng} / \mathrm{mL} / 16 \mathrm{~h})$ even at a lower oral dose $(600 \mu \mathrm{M})$ despite of the different Tmax (4h), which may be attributed to a slow and controlled release of lutein from CA-SA nanocomposite.

The Cmax and AUC values of lutein in the liver of LNCs group displayed higher (2.5 and 2.7 fold) compared to control $(P \leq 0.05)$ despite the identical Tmax ( $8 \mathrm{~h}$ ). Similarly, higher Cmax and AUC values of lutein were obvious in the eyes (3.3 and 5.2 fold) of LNCs group compared to control (Table 2). Results establish that the lutein bioavailability (plasma response) and distribution to the target organs (eye and liver) from LNCs were higher, may be due to the hydrophobic lutein and polymers. D. Liu, Mori, and Huang (1992) have studied the biodistribution of the radioisotope-labelled liposomes with 30-400 nm size in a mice model upon intravenous injection. They have found that the nanoparticles with a mean diameter of $100 \mathrm{~nm}$ revealed prolonged blood circulation and higher liver uptake. The present study also shows higher levels of lutein from LNCs in circulation and liver that could be due to the smaller size of LNCs (Fig. 2D). After oral administration of LNCs, it was found that lutein distributed and accumulated mostly in the liver, followed by the eye (Fig. 3 B \& 3C). This tendency is almost consistent with previous reports (Sato et al., 2011; Yonekura, Kobayashi, Terasaki, \& Nagao, 2010). Also, an interesting study by D. Chang et al. (2018) reported that the nanocrystal formulation of lutein $(10 \mathrm{mg} / \mathrm{kg} \mathrm{BW})$ administered orally to rats showed a higher Cmax $(455.85 \pm 59.76 \mathrm{ng} / \mathrm{mL})$ at Tmax of $3 \mathrm{~h}$. In comparison, the present study results showed lower $\mathrm{Cmax}(182.85 \pm 16.5 \mathrm{ng} / \mathrm{mL})$. The possible reason for higher Cmax could be due to the higher oral dose of lutein nanocrystal $(10 \mathrm{mg} / \mathrm{kg} \mathrm{BW})$ admistered in the above mentioned study. Moreover, a lower dose ( $600 \mu \mathrm{M}$ or $0.5 \mathrm{mg} / \mathrm{kg} \mathrm{BW})$ of LNCs admistered in the present study displayed a relatively higher Cmax compared to the study as mentioned earlier (D. Chang et al., 2018). Further, the lipid composition of any preparation plays a vital role in the carotenoid bioavailability. Use of oleic acid in the LNCs found to help in better intestinal uptake of lutein (Lakshminarayana et al., 2006). The higher intestinal absorption of lutein from LNCs with oleic acid after a week human trial showed $~ 1$.3-fold higher bioavailability compared to lutein delivered in pills (Vishwanathan et al., 2009). Shanmugam et al. (2011) have reported higher bioavailability of lutein (4-11 fold) from oleic acid microemulsion in rats. These findings demonstrate that the inclusion of oleic acid in LNCs supports higher lutein bioavailability.

In order to find out the pharmacokinetics of lutein from LNCs in the diabetic model compared to the control model, the groups were intubated a single dose $(600 \mu \mathrm{M})$ of micellar lutein (control) or LNCs and the results of postprandial plasma, liver and eye lutein responses are shown in Fig. 3D, 3E and 3F. No difference was found in the pattern of pharmacokinetics (absorption and tissue distribution) of lutein from micelles and LNCs fed to diabetic rats. However, lower lutein concentration was found in the diabetic rats compared to normal healthy rats. The Cmax $(67.66 \pm 6.8 \mathrm{ng} / \mathrm{mL})$ and AUC $(373.4 \pm 26 \mathrm{ng} / \mathrm{mL} / 16 \mathrm{~h})$ of lutein from the LNCs group were found to be significantly higher (Cmax, $182.85 \pm 16.5 \mathrm{ng} / \mathrm{mL}$; AUC, $1158.5 \pm 43 \mathrm{ng} / \mathrm{mL} / 16 \mathrm{~h}$ ) by 2.7 and 7.3 folds than the micellar group (Table 3). Nevertheless, the Tmax (4 h) is similar in both groups. Interestingly, plasma lutein was higher 
even after $16 \mathrm{~h}$ in the diabetic rats fed on LNCs signifying a steady-state release (Fig. 2F) suggesting controlled lutein release from nanocomplex (Mukerjee \& Vishwanatha, 2009). Alike, higher T1/2 (6.60 $\pm 0.8 \mathrm{~h}), \mathrm{MRT}(8.0 \pm 1 \mathrm{~h})$ and lower $\mathrm{Cl}(0.088 \pm 0.01$ $\mathrm{ng} /(\mathrm{ng} / \mathrm{mL}) / \mathrm{h})$ of LNCs indicate sustained circulation of lutein in diabetic condition, may be to protect the cells from oxidative stress caused by diabetes (Li \& Huang, 2008). Results further suggest that owing to sustained benefits, LNCs prepared in this study could be considered for delivery of lutein to manage diabetic mediated complications like cataract and retinopathy (Padmanabha \& Vallikannan, 2018). As in the case of plasma lutein, the liver Cmax and AUC of lutein from LNCs have shown significantly higher by 2.6 and 3.4 folds compared to the micellar group (Table 3, Fig. 2E). Similarly, despite the same Tmax (12 h), lutein level in the eyes of LNCs group was higher by 4.04 and 2.80 folds (Cmax, $28.89 \pm 2.9 \mathrm{ng} / \mathrm{g} ; \mathrm{AUC}, 1588 \pm 43.1 \mathrm{ng} / \mathrm{g} / 16 \mathrm{~h}$ ) compared to the control group.

Macular pigment density is well correlated with dietary intakes and plasma concentrations of lutein (Hammond Jr et al., 1996; T Landrum et al., 1997). LNCs constructed could be a prospective therapeutic tool for the treatment of ocular complications owing to higher lutein bioavailability and radical scavenging property. Wang et al. (2007) have described that $52 \%$ of lutein was transported to the retina by HDL and $22 \%$ by LDL from dietary lutein and zeaxanthin in AMD patients. Connor, Duell, Kean, and Wang (2007) have also reported similar findings that HDL-deficient WHAM Chicks having a mutant ABCA1 transporter, HDL plays a prime role in the transport of lutein to the retina. However, in the STZ induced diabetic rats, lower levels (22\%) of HDL (Fig. 4A) and higher (15\%) levels LDL (Fig. 4B) compared to normal healthy rats were observed. However, on treatment with LNCs, the HDL level was reverted to the normal levels. This could be the possible reason for the higher retinal level (eye Cmax- $28.89 \pm 2.9 \mathrm{ng} / \mathrm{mL}$ and AUC - $1588 \pm 43.1 \mathrm{ng} / \mathrm{g} / 16 \mathrm{~h}$, Table 3 ) of lutein from LNCs.

An oral administration of micellar lutein and LNCs to rats peaked maximum in the plasma at $4 \mathrm{~h}$, as reported earlier by Lakshminarayana et al. (2006) and Ranganathan et al. (2019). Further, the tissue biodistribution of lutein from mixed micelles and LNCs found in this study is also in line with other pharmacokinetic studies (Kamil et al., 2016; Ranganathan et al., 2019; Sato et al., 2011). They have reported an accumulation of lutein in the liver and eyes of rats fed lutein-PLGA-NCs orally or intravenously. Overall, the pharmacokinetic pattern of absorption and tissue distribution of lutein from mixed micelles and LNCs in the diabetic rats were almost similar to normal healthy rats. Arunkumar et al. (2013) have reported that an acute dose (200 $\mu \mathrm{M})$ of lutein loaded chitosan nanocapsules to mice displayed 2 fold higher lutein bioavailability (plasma, liver and eye levels) compared to micellar lutein. Results of the current study suggest that LNCs support the intestinal uptake and tissue (plasma, liver, and eye) distribution of lutein from LNCs. The bioavailability of lutein from LNCs found in the current study is significantly higher in plasma (3000 folds), liver ( 855 folds) and eye (739 folds) than PLGA-NCs reported by Ranganathan et al. (2019) which may be due to smaller particle size $(98 \mathrm{~nm}$ ), coating polymers (natural CS-SA) and the lipid core (oleic acid) (Lakshminarayana et al., 2006; Li \& Huang, 2008). Based on the results, we propose that LNCs could be adopted to deliver lutein to target tissue like retina.

Table 2 Pharmacokinetic parameter of plasma, liver and eye responses of micellar lutein and lutein from LNCs after the single oral dose to normal healthy rats. 


\begin{tabular}{|c|c|c|c|c|c|c|}
\hline \multirow{2}{*}{ Parameters } & \multicolumn{2}{|c|}{ Plasma } & \multicolumn{2}{|l|}{ Liver } & \multicolumn{2}{|c|}{ Eye } \\
\hline & $\begin{array}{c}\text { Micellar } \\
\text { lutein } \\
\text { (control) }\end{array}$ & LNCS & $\begin{array}{l}\text { Micellar } \\
\text { lutein } \\
\text { (Control) }\end{array}$ & LNCs & $\begin{array}{l}\text { Micellar } \\
\text { lutein } \\
\text { (Control) } \\
\end{array}$ & LNCS \\
\hline $\mathrm{T} \max (\mathrm{h})$ & 4 & 4 & 8 & 8 & 12 & 12 \\
\hline $\mathrm{T} 1 / 2(\mathrm{~h})$ & $1.56 \pm 1.2$ & $3.62 \pm 0.2^{*}$ & $2.16 \pm 0.2$ & $\begin{array}{l}5.22 \pm \\
0.3^{*}\end{array}$ & $9.63 \pm 0.7$ & $28.01 \pm 1.3^{*}$ \\
\hline $\begin{array}{l}\text { Cmax }(\mathrm{ng} / \mathrm{mL} \text { or } \\
\mathrm{g})\end{array}$ & $67.66 \pm 6.8$ & $182.85 \pm 16.5^{*}$ & $36.8 \pm 2.4$ & $\begin{array}{l}89.6 \pm \\
9.8^{*}\end{array}$ & $12.26 \pm 1.1$ & $39.84 \pm 6.4^{*}$ \\
\hline Clast (ng/mL or $\mathrm{g})$ & $1.86 \pm 0.05$ & $12.21 \pm 0.9 *$ & $8.1 \pm 1.7$ & $\begin{array}{l}10.3 \pm \\
0.8\end{array}$ & $1.26 \pm 0.1$ & $6.54 \pm 0.8^{*}$ \\
\hline $\begin{array}{l}\text { AUC (ng/mL/16h } \\
\text { or g) }\end{array}$ & $373.4 \pm 26$ & $1158.5 \pm 43^{*}$ & $64.52 \pm 11.4$ & $\begin{array}{r}728.9 \\
\pm 22.1^{*}\end{array}$ & $106.4 \pm 7.1$ & $554.2 \pm 12 *$ \\
\hline $\begin{array}{l}\text { AUMC } \\
(\mathrm{ng} / \mathrm{mL} / 16 \mathrm{~h} \text { or } \mathrm{g})\end{array}$ & $1995.1 \pm 39$ & $9955.7 \pm 57 *$ & $2575.5 \pm 11.9$ & $\begin{array}{r}7017.5 \\
\pm 29.3^{*}\end{array}$ & $1401 \pm 13$ & $17818 \pm 56^{*}$ \\
\hline MRTlast (h) & $11.16 \pm 1.1$ & $17.64 \pm 2.0$ & $5.9 \pm 0.4$ & $\begin{array}{l}7.97 \pm \\
0.3\end{array}$ & $13.2 \pm 1.9$ & $32.1 \pm 6.7^{*}$ \\
\hline $\begin{array}{l}\text { CI } \\
(\mathrm{ng} /(\mathrm{ng} / \mathrm{mL}) / \mathrm{h})\end{array}$ & $0.33 \pm 0.01$ & $\begin{array}{l}0.0054 \pm \\
0.001 *\end{array}$ & $0.93 \pm 0.1$ & $\begin{array}{r}0.09 \pm \\
0.01 * \\
\end{array}$ & $0.65 \pm 0.01$ & $\begin{array}{l}0.13 \pm \\
0.01 * \\
\end{array}$ \\
\hline
\end{tabular}

Values are mean $\pm \mathrm{SD}(\mathrm{n}=3)$. Tmax - time to reach maximum concentration, T1/2 - half-life of the drug, Cmax maximum plasma concentration, AUC - Area under the curve of plasma concentration as a function of time, AUMC - Area under the Moment Curve, MRT - mean resident time, CI -

clearance, LNCs - lutein loaded nanocarrier system. $* \mathrm{P} \leq 0.05$

Table 3 Pharmacokinetic parameter of plasma, liver, eye responses of micellar lutein and lutein from LNCs after a single oral dose to diabetic rats.

\begin{tabular}{|c|c|c|c|c|c|c|}
\hline \multirow[t]{2}{*}{ Parameters } & \multicolumn{2}{|c|}{ Plasma } & \multicolumn{2}{|c|}{ Liver } & \multicolumn{2}{|c|}{ Eye } \\
\hline & $\begin{array}{l}\text { Micellar } \\
\text { lutein } \\
\text { (Control) }\end{array}$ & $\overline{\mathrm{LNCS}}$ & $\begin{array}{l}\text { Micellar } \\
\text { lutein } \\
\text { (Control) }\end{array}$ & LNCs & $\begin{array}{l}\text { Micellar } \\
\text { lutein } \\
\text { (Control) }\end{array}$ & LNCs \\
\hline$T \max (\mathrm{h})$ & 4 & 4 & 8 & 8 & 12 & 12 \\
\hline $\mathrm{T} 1 / 2(\mathrm{~h})$ & $4.06 \pm 0.2$ & $\begin{array}{l}6.60 \pm \\
0.8\end{array}$ & $1.6 \pm 0.1$ & $\begin{array}{l}5.63 \pm \\
0.8^{*}\end{array}$ & $11.0 \pm 0.1$ & $43.6 \pm 2.4^{*}$ \\
\hline $\mathrm{C}_{\max }(\mathrm{ng} / \mathrm{mL}$ or $\mathrm{g})$ & $15.25 \pm 1.6$ & $\begin{array}{l}76.70 \pm \\
8.9^{*}\end{array}$ & $23.7 \pm 2.2$ & $\begin{array}{r}62.3 \pm \\
3.1 *\end{array}$ & $7.15 \pm 1.3$ & $28.89 \pm 2.9 *$ \\
\hline Clast $(\mathrm{ng} / \mathrm{mL}$ or $\mathrm{g})$ & $9.84 \pm 0.7$ & $\begin{array}{l}20.15 \pm \\
2.1 *\end{array}$ & $6.3 \pm 0.6$ & $\begin{array}{l}8.7 \pm \\
0.8\end{array}$ & $6.82 \pm 1.7$ & $22.6 \pm 3.2 *$ \\
\hline $\begin{array}{l}\text { AUC }(n g / m L / 16 h \\
\text { or g) }\end{array}$ & $120.4 \pm 7.6$ & $\begin{array}{l}767.9 \pm \\
19 *\end{array}$ & $165.5 \pm 6.6$ & $\begin{array}{r}562.91 \pm \\
12^{*}\end{array}$ & $569 \pm 29.2$ & $\begin{array}{l}1588 \pm \\
43.1 *\end{array}$ \\
\hline $\begin{array}{l}\text { AUMC (ng/mL/16h } \\
\text { or g) }\end{array}$ & $686.7 \pm 16$ & $\begin{array}{l}4565.7 \pm \\
27 *\end{array}$ & $3264.5 \pm 18$ & $\begin{array}{r}5561.1 \underset{2}{ \pm} \\
\pm 7^{*}\end{array}$ & $\begin{array}{r}1172.5 \pm \\
76.1\end{array}$ & $\begin{array}{l}19930 \pm \\
129 *\end{array}$ \\
\hline MRTlast (h) & $5.70 \pm 1.3$ & $\begin{array}{l}8.0 \pm \\
1.6^{*}\end{array}$ & $6.75 \pm 0.2$ & $9.9 \pm 0.9 *$ & $2.90 \pm 0.2$ & $10.3 \pm 0.7^{*}$ \\
\hline $\mathrm{CI}(\mathrm{ng} /(\mathrm{ng} / \mathrm{mL}) / \mathrm{h})$ & $0.54 \pm 0.01$ & $\begin{array}{l}0.088 \pm \\
0.01 *\end{array}$ & $0.06 \pm 0.01$ & $\begin{array}{r}0.12 \pm \\
0.01\end{array}$ & $0.89 \pm 0.01$ & $0.21 \pm 0.01$ \\
\hline
\end{tabular}

Values are mean \pm SD $(n=3)$. Tmax - time to reach maximum concentration, T1/2 - half-life of the drug, Cmax - maximum plasma concentration, AUC

- Area under the curve of plasma concentration as a function of time, AUMC - Area under the Moment Curve, MRT - mean resident time, $\mathrm{Cl}$ - clearance, LNCs - lutein loaded nanocarrier system. *P $\leq 0.05$

\section{ARPE-19 cell viability}

Potential cytotoxicity of LNCs to human retinal pigmental epithelial cells (ARPE-19) was examined by MTT assay. Figure 5A demonstrates that LNCs (0-50 $\mu \mathrm{M}$ of lutein) did not affect the viability of ARPE-19 cells compared to control cells. Therefore, 10 $\mu \mathrm{M}$ concentration of LNCs (1/5th) was used for the treatment in further experiments. 
Diabetes/hyperglycemia induces oxidative stress (OS) by generating pre radicals (Asmat, Abad, \& Ismail, 2016). Hence, to find out the radical scavenging and cell protective property of LNCs, OS was induced by treating cells with H2O2. Therefore, initially, ARPE19 cells were exposed to $\mathrm{H} 2 \mathrm{O} 2(150 \mu \mathrm{M})$ for different time intervals up to $24 \mathrm{~h}$ and monitored the intracellular ROS level by DCFDA dye to ascertain oxidative stress (Fig. 5B). The intracellular ROS has significantly increased from $1 \mathrm{~h}$ to $2 \mathrm{~h}$ and from $2 \mathrm{~h}$ afterward, no significant alteration was noticed. Hence, $2 \mathrm{~h}$ exposure time was considered for subsequent studies. To find out the protective effect of lutein, cells were treated with an equimolar concentration of LNCs and micellar lutein $(10 \mu \mathrm{M})$ prior to exposure to $\mathrm{H} 2 \mathrm{O} 2$ for $24 \mathrm{~h}$ which resulted in $50 \%$ cell death. Whereas, pre-treatment with micellar lutein and LNCs significantly attenuated H2O2 induced cell death by $63 \%$ and 79\%, respectively (Fig. 5C). H. Liu et al. (2017) have reported that lutein at $10 \mu \mathrm{M}$ has reversed the reduction of RPE cell viability under $\mathrm{H} 2 \mathrm{O} 2$ persuaded OS conditions by $65.4 \%$. In the present study, LNCs displayed higher (79\%) RPE-19 cell viability than micellar lutein, indicating greater cellular uptake and scavenging intracellular ROS. The higher efficacy of LNCs, the smaller particle size and slow and controlled lutein release from LNCs compared to micelles could be the reason for higher cell viability (Mukerjee \& Vishwanatha, 2009; Niamprem et al., 2014).

\section{Cellular Uptake of lutein}

ARPE-19 cells were treated with LNCs or micellar lutein $((10 \mu \mathrm{M})$ to find out cellular Uptake of lutein. No reduction in the cell number or cell death was observed in LNCs treatment, demonstrating a safe level of NCs delivered. Cellular lutein uptake from LNCs was higher $(17.6 \mathrm{ng} / \mathrm{mg})$ compared to micelles $(9.5 \mathrm{ng} / \mathrm{mg})$ at $18 \mathrm{~h}$ in the $\mathrm{H} 2 \mathrm{O} 2(150 \mu \mathrm{M}$ for $2 \mathrm{~h})$ treated cells (Fig. 6A). Over the period of $24 \mathrm{~h}$ treatment, in control cells (not exposed to H2O2), there was a non-significant decrease in the lutein uptake (6.3 and $15.6 \mathrm{ng} / \mathrm{mg}$ ) from mixed micelles and LNCs. As discussed earlier in animal experiment, the higher lutein uptake from LNCs may be due to their nanosize and higher surface to volume ratio (Deming \& Erdman, 1999; S.-S. Feng, 2004; Mukerjee \& Vishwanatha, 2009; Niamprem et al., 2014). It is well documented that particle size plays a critical factor in cellular uptake, release kinetics and stability of active compounds (S.-S. Feng, 2004; Niamprem et al., 2014). However, cellular lutein uptake patterns from LNCs and mixed micelles are similar between H2O2 treated and control ARPE-19 cells. Interestingly, lutein uptake is significantly higher by 2 fold $(12.1 \mathrm{ng} / \mathrm{mg})$ from mixed micelles and 1.5 folds $(21.6 \mathrm{ng} / \mathrm{mg})$ from LNCs in H2O2 treated (Fig.6B) groups compared to control cells and $\mathrm{H} 2 \mathrm{O} 2(150 \mu \mathrm{M}$ for $2 \mathrm{~h}$ ) treatment did not cause a reduction in the cell number (Fig. 6C). The possible reason for high cellular lutein uptake from LNCs under $\mathrm{H} 2 \mathrm{O} 2$ could be due to enhanced cell permeability persuaded by the $\mathrm{H} 2 \mathrm{O} 2$.

Since lutein uptake at $18 \mathrm{~h}$ was maximum, $18 \mathrm{~h}$ treatment time was considered as the working parameters for the subsequent studies.

\section{LNCs attenuates the H2O2 generated oxidative stress}

The imbalance between antioxidants and pro-oxidants in hyperglycemia leads to oxidative stress owing to the release of ROS beyond the limits of clearance from circulation and cells. Such a condition results in functional and morphological impairment in retinal pigment epithelium (RPE), endothelial cells, and retinal ganglion cells (He et al., 2014; Sharavana \& Baskaran, 2017). We have hypothesized that the delivery of lutein as LNCs could greatly modulate the intracellular ROS than micellar lutein in ARPE-19 cells under $\mathrm{H} 2 \mathrm{O} 2$ induced oxidative stress. ROS levels were measured in ARPE-19 cells upon $\mathrm{H} 2 \mathrm{O} 2$ treatment and followed by treatment with either micellar lutein or LNCs (Fig. 7). Results showed 5.3 fold increase in ROS level in H2O2 treatment compared to control (no H2O2 treated) and vehicle control, indicating that vehicle has no role in ROS release. Cells pre- treated with micellar lutein or LNCs $(10 \mu \mathrm{M})$ significantly reduced the intracellular ROS level by 2 folds suggesting that LNCs had greatly ameliorated the intracellular ROS compared to micellar lutein, might be due to higher cellular lutein uptake from LNCs. Other possible reasons for ROS lowering effect could be the slow and sustainable release of lutein from natural polymers CS and SA (S.-S. Feng, 2004; Niamprem et al., 2014). Chae, Park, and Park (2018) also reported that lutein (10 $\mu \mathrm{M})$ treatment prior to H2O2 (100 $\mu \mathrm{M}$ for $2 \mathrm{~h})$, decreased the ROS levels (26.03\%) in ARPE-19 cells. However, lutein delivered in NCs developed in the current study efficiently brought back the intracellular ROS to the normal level. We have demonstrated that LNCs suppress H2O2-induced oxidative stress. 
Oxidative stress persuades detrimental alterations in mitochondria and its membrane potential (DYm) of RPE cells that can upset mitochondrial homeostasis that may be one of the central cause factors in retinal pathogenesis (Blasiak, Pawlowska, Szczepanska, \& Kaarniranta, 2019). Alteration of mitochondrial membrane potential (DYm) affects its functions. To find out the role of LNCs on the up-regulation of DYm under H2O2 induced OS in ARPE-19 cells by examining the ratio of red/green fluorescence intensity of JC-1 staining. Exposure of ARPE-19 cells to $150 \mu \mathrm{M} \mathrm{H} 202$ resulted in rapid loss (49\%) of DYm, as seen by an increase in the DYm fluorescence intensity (Fig. 8). Pre-treatment with micellar lutein or LNCs (10 $\mu$ M) for $18 \mathrm{~h}$ found to attenuate DYm by $67 \%$ and $88 \%$ suggesting that LNCs render better protection and maintenance of DYm homeostasis compared to micellar lutein indicating a possible advantage of nanosize and surface charge of LNCs over the micellar lutein (S.-S. Feng, 2004; Niamprem et al., 2014).

\section{Conclusion}

LNCs developed in this study are proficient to improve the solubility and physiological stability of lutein, which could be one of the reasons for the improved intestinal uptake, plasma and tissue (retina) responses of lutein in both normal and $\mathrm{H} 2 \mathrm{O} 2$ induced OS in ARPE- 19 cells. However, the molecular transport mechanism of LNCs across intestinal and retinal epithelial cells needs a detailed investigation. The higher bioavailability of lutein in retinal cells and in vitro and rat retina in vivo from LNCs might be due to the nanosized $(\leq 100 \mathrm{~nm}$ ) LNCs with natural polymers CS and SA in addition to oleic acid. Higher encapsulation efficiency, stability and self-assembling property of oleic acid in LNCs have delivered greater potential towards the enhanced lutein bioavailability. Further, for the first time, to the best of our knowledge, LNCs have been prepared completely with natural polymers and examined for lutein delivery in the $\mathrm{H} 2 \mathrm{O} 2$ induced OS model. However, a detailed study with hyperglycemia induced model is warranted to validate the present results. Thus, LNCs may be considered as a potential carrier system for macular carotenoid lutein to the ocular tissue to diminish OS in retinopathy, cataract and macular degeneration. Results unveil that the CS- SA-OL nanocarrier scaffold could serve as more efficient carrier than synthetic polymers or lipid alone for the delivery of lipophilic bioactive to aid AMD, cataract and diabetic retinopathy.

\section{Declarations}

\section{Declaration of Competing Interest}

The authors declare no conflict of interest.

\section{Acknowledgment}

Veeresh T greatly acknowledges the Department of Biotechnology (DBT), Government of India, for financial assistance for awarding Senior Research Fellowship (Award No. DBT/JRF/BET-16/1/2016/AL/54-438). The authors are grateful to Dr. N. S. Mahendrakar, Ex-Chief Editor, Journal of Food Science and Technology (Mysore), for editing the manuscript for its English language.

\section{References}

Arunkumar, R., Prashanth, K. V. H., \& Baskaran, V. (2013). Promising interaction between nanoencapsulated lutein with low molecular weight chitosan: characterization and bioavailability of lutein in vitro and in vivo. Food chemistry, 141(1), $327-337$.

Asmat, U., Abad, K., \& Ismail, K. (2016). Diabetes mellitus and oxidative stress-A concise review. Saudi Pharmaceutical Journal, 24(5), 547-553.

Bernstein, P. S., Li, B., Vachali, P. P., Gorusupudi, A., Shyam, R., Henriksen, B. S., \& Nolan, J. M. (2016). Lutein, zeaxanthin, and mesozeaxanthin: The basic and clinical science underlying carotenoid-based nutritional interventions against ocular disease. Progress in retinal and eye research, 50, 34-66. 
Blasiak, J., Pawlowska, E., Szczepanska, J., \& Kaarniranta, K. (2019). Interplay between autophagy and the ubiquitin-proteasome system and its role in the pathogenesis of age-related macular degeneration. International journal of molecular sciences, 20(1), 210.

Boon, C. S., McClements, D. J., Weiss, J., \& Decker, E. A. (2010). Factors influencing the chemical stability of carotenoids in foods. Critical reviews in food science and nutrition, 50(6), 515-532.

Chae, S. Y., Park, S. Y., \& Park, G. (2018). Lutein protects human retinal pigment epithelial cells from oxidative stress-induced cellular senescence. Molecular medicine reports, 18(6), 5182-5190. Chandıa, N., Matsuhiro, B., \& Vásquez, A. (2001). Alginic acids in Lessonia trabeculata: characterization by formic acid hydrolysis and FT-IR spectroscopy. Carbohydrate Polymers, 46(1), 81-87.

Chang, D., Ma, Y., Cao, G., Wang, J., Zhang, X., Feng, J., \& Wang, W. (2018). Improved oral bioavailability for lutein by nanocrystal technology: formulation development, in vitro and in vivo evaluation. Artificial cells, nanomedicine, and biotechnology, 46(5), 1018-1024.

Chang, J., Zhang, Y., Li, Y., Lu, K., Shen, Y., Guo, Y., . . Zhang, S. (2018). NrF2/ARE and NF-kB pathway regulation may be the mechanism for lutein inhibition of human breast cancer cell. Future Oncology, 14(8), 719-726.

Chen, B., Le, W., Wang, Y., Li, Z., Wang, D., Ren, L., . . Hu, Y. (2016). Targeting negative surface charges of cancer cells by multifunctional nanoprobes. Theranostics, 6(11), 1887.

Connor, W. E., Duell, P. B., Kean, R., \& Wang, Y. (2007). The prime role of HDL to transport lutein into the retina: evidence from HDLdeficient WHAM chicks having a mutant ABCA1 transporter. Investigative ophthalmology \& visual science, 48(9), 4226-4231.

Deming, D. M., \& Erdman, J. W. (1999). Mammalian carotenoid absorption and metabolism. Pure and Applied Chemistry, 71(12), 2213-2223.

Dodero, A., Vicini, S., Alloisio, M., \& Castellano, M. (2019). Sodium alginate solutions: correlation between rheological properties and spinnability. Journal of materials science, 54(10), 8034- 8046.

Driver, A. S., Kodavanti, P. R. S., \& Mundy, W. R. (2000). Age-related changes in reactive oxygen species production in rat brain homogenates. Neurotoxicology and teratology, 22(2), 175- 181.

Du, X.-J., Wang, J.-L., Iqbal, S., Li, H.-J., Cao, Z.-T., Wang, Y.-C., . . Wang, J. (2018). The effect of surface charge on oral absorption of polymeric nanoparticles. Biomaterials science, 6(3), 642-650.

Farshid, A., \& Lakshmi, C. (2017). Formulation of nanoparticles of anti-migraine drugs triptans by coacervation method. drugs, 5 , 6.

Feng, H., Li, C., Tan, C. P., Fu, X., Zhang, B., \& Huang, Q. (2017). Physicochemical properties and in vitro bioaccessibility of lutein loaded emulsions stabilized by corn fiber gums. RSC advances, 7(61), 38243-38250.

Feng, S.-S. (2004). Nanoparticles of biodegradable polymers for new-concept chemotherapy. Expert review of medical devices, $1(1), 115-125$.

Filippov, M., \& Kohn, R. (1974). Determination of composition of alginates by infrared spectroscopic method. Chem zvesti, 28(6), 817-819.

Frede, K., Henze, A., Khalil, M., Baldermann, S., Schweigert, F. J., \& Rawel, H. (2014). Stability and cellular uptake of lutein-loaded emulsions. Journal of functional foods, 8, 118-127.

Hammond Jr, B. R., Curran-Celentano, J., Judd, S., Fuld, K., Krinsky, N. I., Wooten, B. R., \& Snodderly, M. (1996). Sex Differences in Macular Pigment Optical Density:: Relation to Plasma Carotenoid Concentrations and Dietary Patterns. Vision research, 36(13), 2001-2012. 
He, Y., Leung, K. W., Ren, Y., Pei, J., Ge, J., \& Tombran-Tink, J. (2014). PEDF improves mitochondrial function in RPE cells during oxidative stress. Investigative ophthalmology \& visual science, 55(10), 6742-6755.

Hemalatha, N., Naveen, J., \& Baskaran, V. (2019). Medicinal Plants as Sources of Retina Protective Carotenoids (Lutein, $\beta$ carotene) and their Radical Scavenging Property. Indian Journal of Nutrition and Dietetics, 56(4), 365-379.

Honary, S., \& Zahir, F. (2013). Effect of zeta potential on the properties of nano-drug delivery systems-a review (Part 1). Tropical Journal of Pharmaceutical Research, 12(2), 255-264.

Jiao, Y., Zheng, X., Chang, Y., Li, D., Sun, X., \& Liu, X. (2018). Zein-derived peptides as nanocarriers to increase the water solubility and stability of lutein. Food \& Function, 9(1), 117-123.

Joint, F., Additives, W. E. C. o. F., \& Organization, W. H. (2005). Evaluation of certain food additives: sixty-third report of the Joint FAO.

Kamil, A., Smith, D. E., Blumberg, J. B., Astete, C., Sabliov, C., \& Chen, C.-Y. O. (2016). Bioavailability and biodistribution of nanodelivered lutein. Food chemistry, 192, 915-923.

Kotake-Nara, E., \& Nagao, A. (2011). Absorption and metabolism of xanthophylls. Marine drugs, 9(6), 1024-1037.

Kumar, P. P., \& KV, H. P. (2019). Low Molecular Weight Chitosan ( $20 \mathrm{kDa})$ protects acrylamide induced oxidative stress in D. melanogaster by restoring dopamine and KIF5B levels. Carbohydrate polymers, 222, 115005.

Kumari, A., Yadav, S. K., \& Yadav, S. C. (2010). Biodegradable polymeric nanoparticles based drug delivery systems. Colloids and surfaces B: biointerfaces, 75(1), 1-18.

Lakshminarayana, R., Raju, M., Krishnakantha, T., \& Baskaran, V. (2006). Enhanced lutein bioavailability by lysophosphatidylcholine in rats. Molecular and cellular biochemistry, 281(1-2), 103.

Lakshminarayana, R., Raju, M., Prakash, M. K., \& Baskaran, V. (2009). Phospholipid, oleic acid micelles and dietary olive oil influence the lutein absorption and activity of antioxidant enzymes in rats. Lipids, 44(9), 799-806.

Li, S.-D., \& Huang, L. (2008). Pharmacokinetics and biodistribution of nanoparticles. Molecular pharmaceutics, 5(4), 496-504.

Lienau, A., Glaser, T., Tang, G., Dolnikowski, G. G., Grusak, M. A., \& Albert, K. (2003). Bioavailability of lutein in humans from intrinsically labeled vegetables determined by LC-APCI-MS. The Journal of nutritional biochemistry, 14(11), 663-670.

Liu, D., Mori, A., \& Huang, L. (1992). Role of liposome size and RES blockade in controlling biodistribution and tumor uptake of GM1-containing liposomes. Biochimica et Biophysica Acta (BBA)-Biomembranes, 1104(1), 95-101.

Liu, H., Liu, W., Zhou, X., Long, C., Kuang, X., Hu, J., . . Huang, Z. (2017). Protective effect of lutein on ARPE-19 cells upon H2O2induced G2/M arrest. Molecular medicine reports, 16(2), 2069- 2074.

Ma, M., Yuan, Y., Yang, S., Wang, Y., \& Lv, Z. (2020). Fabrication and characterization of zein/tea saponin composite nanoparticles as delivery vehicles of lutein. $L W T, 109270$.

Mamatha, B. S., \& Baskaran, V. (2011). Effect of micellar lipids, dietary fiber and $\beta$-carotene on lutein bioavailability in aged rats with lutein deficiency. Nutrition, 27(9), 960-966.

Mohammed, M. A., Syeda, J., Wasan, K. M., \& Wasan, E. K. (2017). An overview of chitosan nanoparticles and its application in non-parenteral drug delivery. Pharmaceutics, 9(4), 53.

Mukerjee, A., \& Vishwanatha, J. K. (2009). Formulation, characterization and evaluation of curcumin- loaded PLGA nanospheres for cancer therapy. Anticancer research, 29(10), 3867-3875. 
Niamprem, P., Rujivipat, S., \& Tiyaboonchai, W. (2014). Development and characterization of lutein- loaded SNEDDS for enhanced absorption in Caco-2 cells. Pharmaceutical development and technology, 19(6), 735-742.

Padmanabha, S., \& Vallikannan, B. (2018). Fatty acids modulate the efficacy of lutein in cataract prevention: Assessment of oxidative and inflammatory parameters in rats. Biochemical and biophysical research communications, 500(2), 435-442.

Rafi, M. M., Kanakasabai, S., Gokarn, S. V., Krueger, E. G., \& Bright, J. J. (2015). Dietary lutein modulates growth and survival genes in prostate cancer cells. Journal of medicinal food, 18(2), 173-181.

Ranganathan, A., Hindupur, R., \& Vallikannan, B. (2016). Biocompatible lutein-polymer-lipid nanocapsules: acute and subacute toxicity and bioavailability in mice. Materials Science and Engineering: C, 69, 1318-1327.

Ranganathan, A., Manabe, Y., Sugawara, T., Hirata, T., Shivanna, N., \& Baskaran, V. (2019). Poly (d, I- lactide-co-glycolide)phospholipid nanocarrier for efficient delivery of macular pigment lutein: absorption pharmacokinetics in mice and antiproliferative effect in Hep G2 cells. Drug delivery and translational research, 9(1), 178-191.

Ravi, H., \& Baskaran, V. (2015). Biodegradable chitosan-glycolipid hybrid nanogels: A novel approach to encapsulate fucoxanthin for improved stability and bioavailability. Food Hydrocolloids, 43, 717-725.

Ridolfo, R., Williams, D. S., \& van Hest, J. C. (2020). The home for the most innovative and exciting polymer chemistry, with an emphasis on polymer synthesis and applications thereof. Image, 11(2791), 2799-2810.

Sadiq, S., Imran, M., Habib, H., Shabbir, S., Ihsan, A., Zafar, Y., \& Hafeez, F. Y. (2016). Potential of monolaurin based food-grade nano-micelles loaded with nisin Z for synergistic antimicrobial action against Staphylococcus aureus. LWT-Food Science and Technology, 71, 227-233.

Sakamuru, S., Attene-Ramos, M. S., \& Xia, M. (2016). Mitochondrial membrane potential assay. In

High-Throughput Screening Assays in Toxicology (pp. 17-22): Springer

Sato, Y., Joumura, T., Nashimoto, S., Yokoyama, S., Takekuma, Y., Yoshida, H., \& Sugawara, M. (2018). Enhancement of lymphatic transport of lutein by oral administration of a solid dispersion and a self-microemulsifying drug delivery system. European Journal of Pharmaceutics and Biopharmaceutics, 127, 171-176.

Sato, Y., Kobayashi, M., Itagaki, S., Hirano, T., Noda, T., Mizuno, S., . . Iseki, K. (2011). Pharmacokinetic properties of lutein emulsion after oral administration to rats and effect of food intake on plasma concentration of lutein. Biopharmaceutics \& drug disposition, 32(3), 151-158.

Seto, Y., Ueno, K., Suzuki, H., Sato, H., \& Onoue, S. (2019). Development of novel lutein nanocrystal formulation with improved oral bioavailability and ocular distribution. Journal of functional foods, 61, 103499.

Shanmugam, S., Baskaran, R., Balakrishnan, P., Thapa, P., Yong, C. S., \& Yoo, B. K. (2011). Solid self- nanoemulsifying drug delivery system (S-SNEDDS) containing phosphatidylcholine for enhanced bioavailability of highly lipophilic bioactive carotenoid lutein. European Journal of Pharmaceutics and Biopharmaceutics, 79(2), 250-257.

Sharavana, G., \& Baskaran, V. (2017). Lutein downregulates retinal vascular endothelial growth factor possibly via hypoxia inducible factor 1 alpha and X-box binding protein 1 expression in streptozotocin induced diabetic rats. Journal of functional foods, 31, 97-103.

Sugawara, T., Kushiro, M., Zhang, H., Nara, E., Ono, H., \& Nagao, A. (2001). Lysophosphatidylcholine enhances carotenoid uptake from mixed micelles by Caco-2 human intestinal cells. The Journal of nutrition, 131(11), 2921-2927.

T Landrum, J., Bone, R. A., Joa, H., D Kilburn, M., Moore, L. L., \& Sprague, K. E. (1997). A one year study of the macular pigment: the effect of 140 days of a lutein supplement. Experimental eye research, 65(1), 57-62. 
Toragall, V., Jayapala, N., Muthukumar, S., \& Baskaran, V. (2020). Biodegradable chitosan-sodium alginate-oleic acid nanocarrier promotes bioavailability and target delivery of lutein in rat model with no toxicity. Food chemistry, 127195.

Toragall, V., Jayapala, N., \& Vallikannan, B. (2020). Chitosan-oleic acid-sodium alginate a hybrid nanocarrier as an efficient delivery system for enhancement of lutein stability and bioavailability. International Journal of Biological Macromolecules, 150, 578-594.

Vishwanathan, R., Wilson, T. A., \& Nicolosi, R. J. (2009). Bioavailability of a nanoemulsion of lutein is greater than a lutein supplement. Nano Biomed Eng, 1(1), 38-49.

Vonarbourg, A., Passirani, C., Desigaux, L., Allard, E., Saulnier, P., Lambert, O., . . Pitard, B. (2009). The encapsulation of DNA molecules within biomimetic lipid nanocapsules. Biomaterials, 30(18), 3197-3204.

Wang, W., Connor, S. L., Johnson, E. J., Klein, M. L., Hughes, S., \& Connor, W. E. (2007). Effect of dietary lutein and zeaxanthin on plasma carotenoids and their transport in lipoproteins in age-related macular degeneration. The American journal of clinical nutrition, 85(3), 762-769.

Wissing, S., Kayser, O., \& Müller, R. (2004). Solid lipid nanoparticles for parenteral drug delivery. Advanced drug delivery reviews, 56(9), 1257-1272.

Wu, W., Li, Y., Wu, Y., Zhang, Y., Wang, Z., \& Liu, X. (2015). Lutein suppresses inflammatory responses through Nrf2 activation and NF-KB inactivation in lipopolysaccharide-stimulated BV-2 microglia. Molecular nutrition \& food research, 59(9), 1663-1673.

Yonekura, L., Kobayashi, M., Terasaki, M., \& Nagao, A. (2010). Keto-carotenoids are the major metabolites of dietary lutein and fucoxanthin in mouse tissues. The Journal of nutrition, 140(10), 1824-1831.

Zhao, Q., Miriyala, N., Su, Y., Chen, W., Gao, X., Shao, L., . . Cao, D. (2018). Computer-aided formulation design for a highly soluble lutein-cyclodextrin multiple-component delivery system. Molecular pharmaceutics, 15(4), 1664-1673.

\section{Figures}

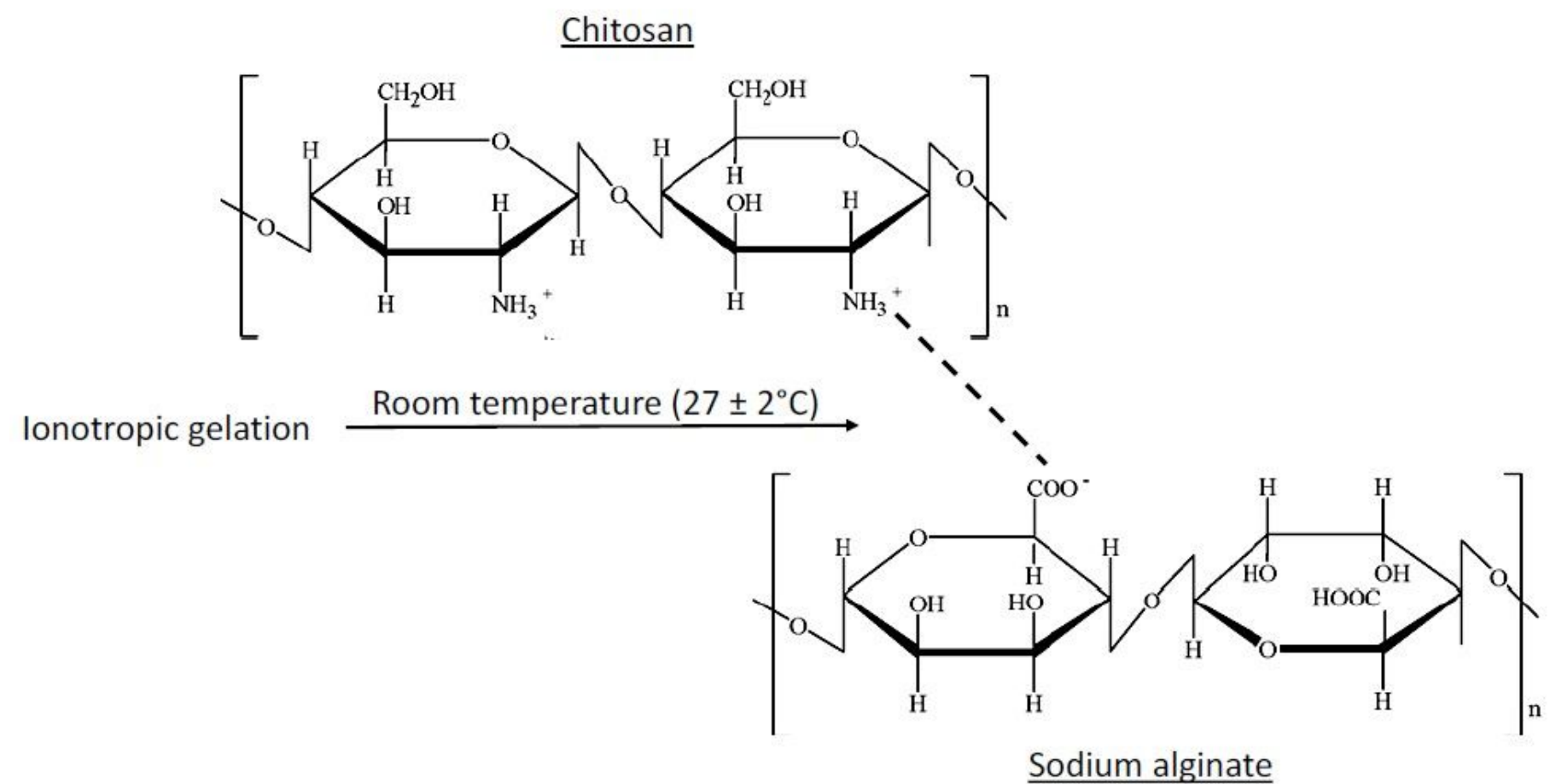

Figure 1 
Chitosan-sodium alginate interaction scaffold

(A) Size (d.n... \% intensity: St Dev (d.n...

$\begin{array}{rllll}\text { Z-Average (d.nm): } 99.04 & \text { Peak 1: } & 139.8 & 100.0 & 79.82 \\ \text { Pdl: } 0.273 & \text { Peak 2: } & 0.000 & 0.0 & 0.000\end{array}$

intercopt: 0.954

Peak 3: $\quad 0.000 \quad 0.0 \quad 0.000$

Result quality Good
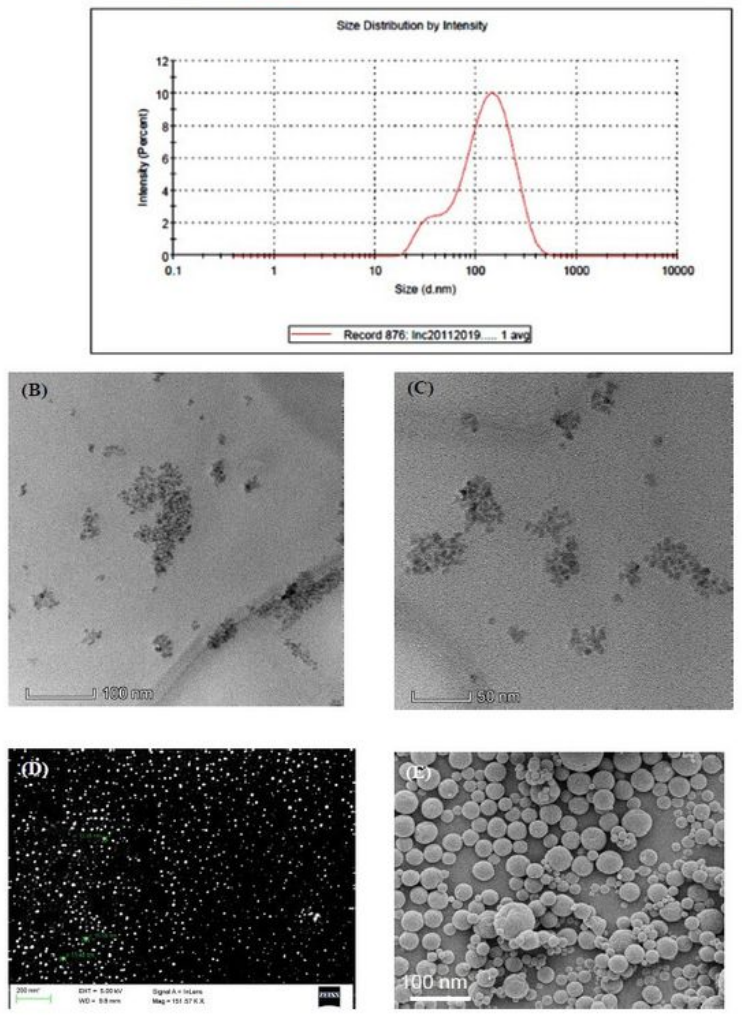

(F)

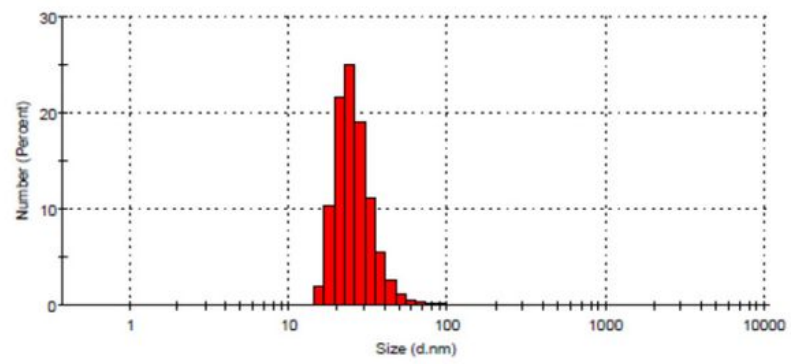

\section{Figure 2}

Particle size of LNCs measured by (A) dynamic light scattering, TEM image at (B) $100 \mathrm{~nm}$ and (C) $50 \mathrm{~nm}$ scale. (D) \& (E) are SEM images and $(F)$ is the histogram representation of size distribution of LNCs. 

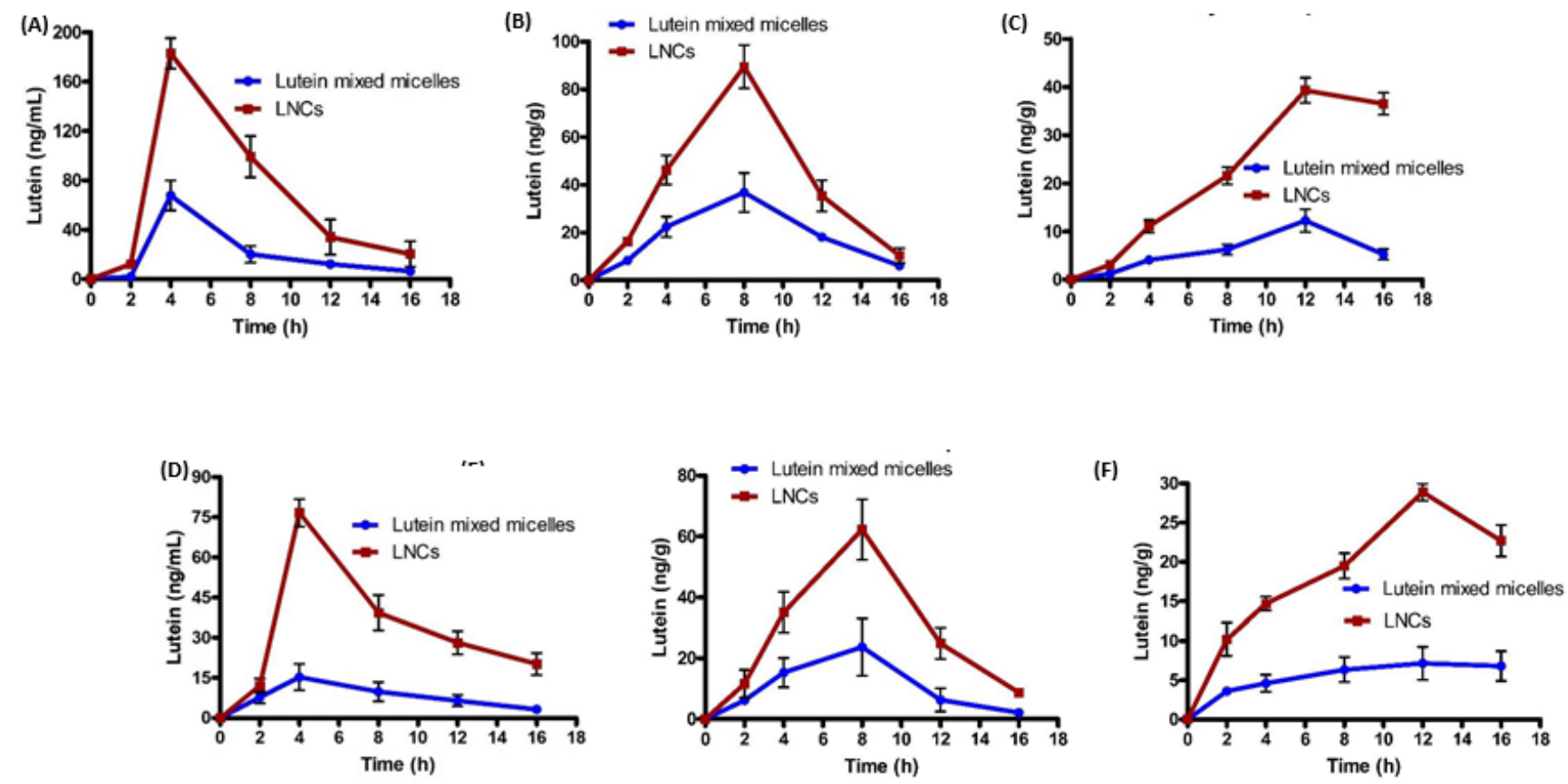

\section{Figure 3}

Pharmacokinetics of lutein from mixed micelles and LNCs (A) plasma (B) liver and (C) eye responses in control animal, (D) plasma (E) liver and (F) eye responses in diabetic rats. Data represented mean $\pm S D(n=3)$.
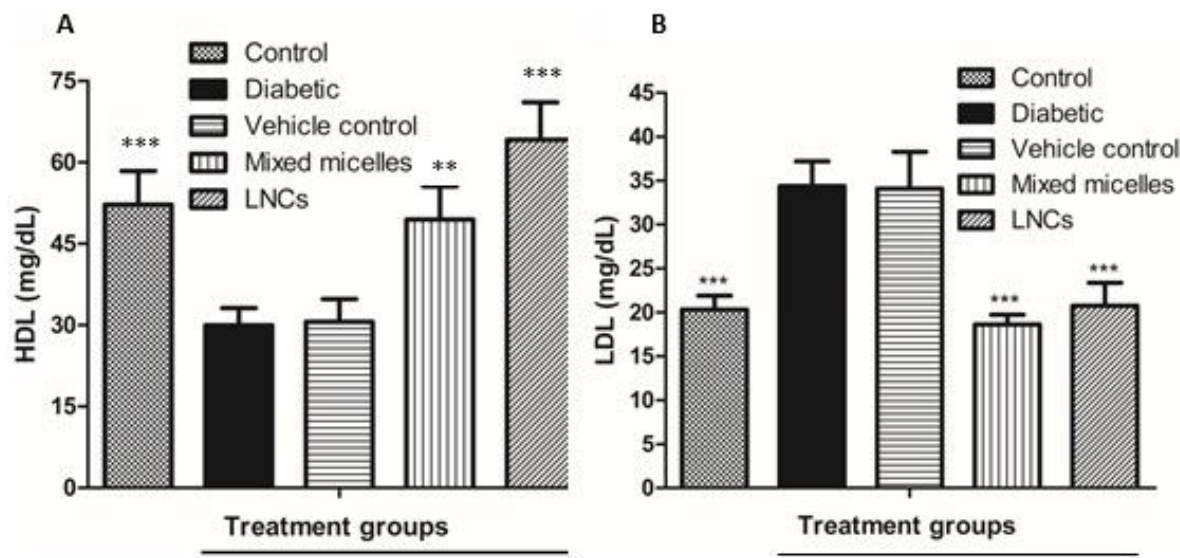

Diabetic

Figure 4

Plasma HDL (A) and LDL (B) levels in diabetic and LNCs treatment groups. Data are 506 expressed as means \pm SEM $(n=3$ per group). ANOVA followed by Tukey's test: ${ }^{* \star} \mathrm{P}<0.05$ versus diabetic control; ${ }^{\star *} \mathrm{P}<0.01$ versus diabetic vehicle. 
(A)

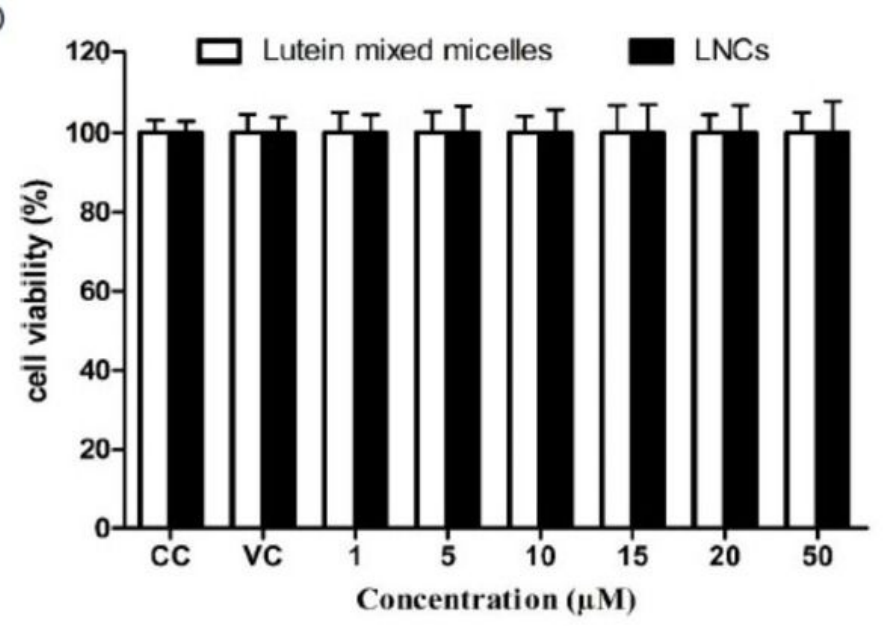

(B)

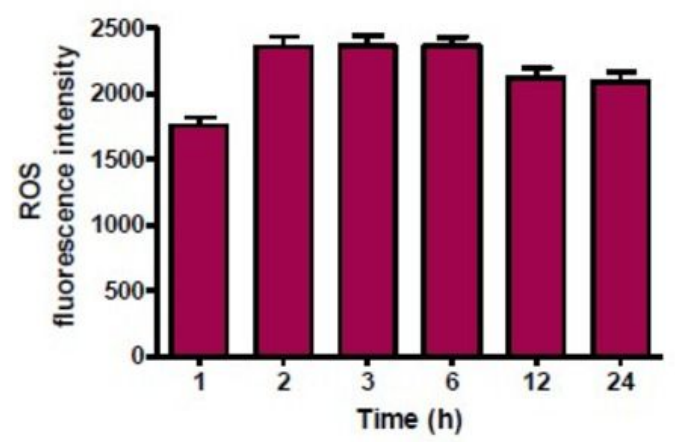

(C)

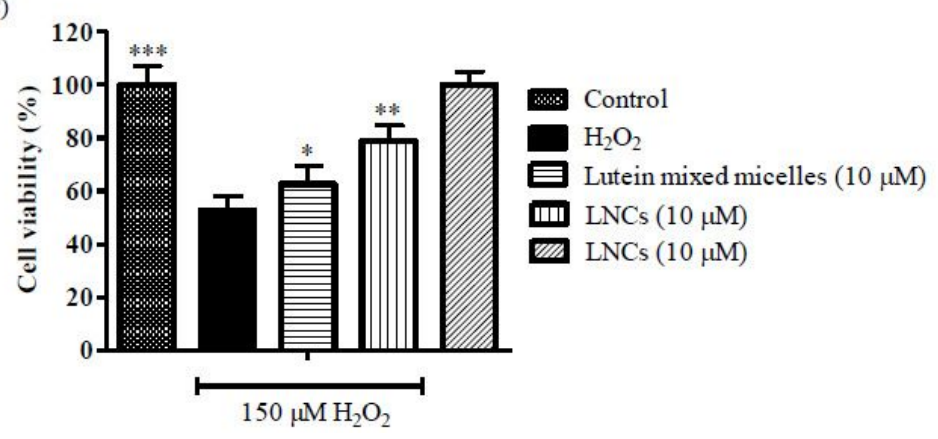

Figure 5

Cytotoxicity of LNCs and micellar lutein (A), H2O2 induced intracellular ROS at different time intervals (B) and cell viability under $\mathrm{H} 2 \mathrm{O} 2$ induced oxidative stress with different treatments. Data are expressed as means \pm SEM $(n=3$ per group). ANOVA followed by Tukey's test: ${ }^{\star \star \star} \mathrm{P}<0.05$ versus $\mathrm{H} 2 \mathrm{O} 2$ treatment; ${ }^{* \star} \mathrm{P}<0.01$ versus $\mathrm{H} 2 \mathrm{O} 2$ treatment. $\mathrm{CC}=\mathrm{Cell}$ control, VC = Vehicle control 

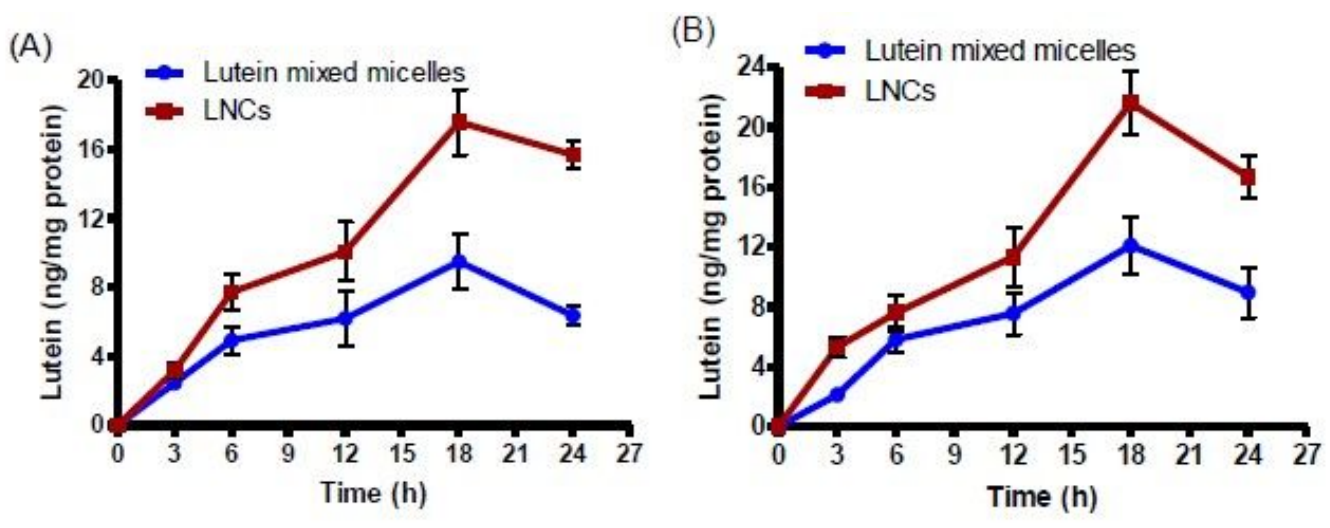

(C)

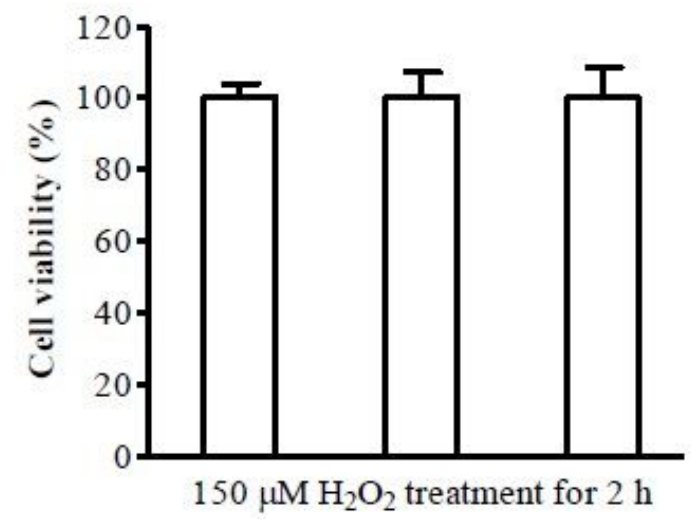

Figure 6

Lutein uptake from mixed micelles and LNCs in control (A) and H2O2 (150 $\mu \mathrm{M}$ for $2 \mathrm{~h}$ ) induced OS (B) ARPE-19 cells and (C) ARPE-19 cell viability after $\mathrm{H} 2 \mathrm{O} 2(150 \mu \mathrm{M}$ for $2 \mathrm{~h})$ treatment. Data represented as mean \pm SD $(n=3)$.
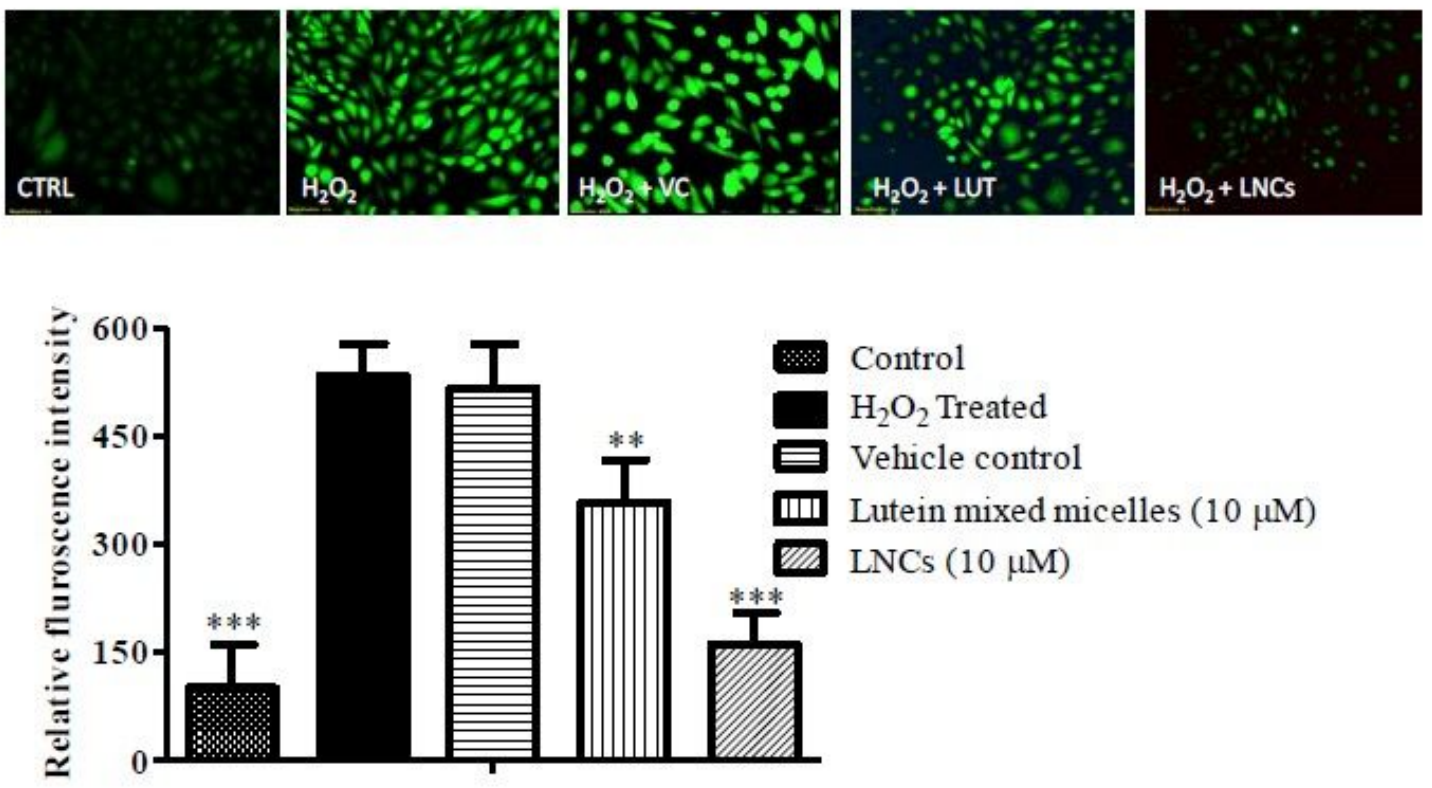

Treatment groups

Figure 7

LNCs attenuate the H2O2 induced intracellular ROS in ARPE-19 cells. Cells were treated with micellar lutein and LNCs (10 $\mu \mathrm{M})$ for $18 \mathrm{~h}$, followed by incubated with or without $150 \mu \mathrm{M}$ of $\mathrm{H} 2 \mathrm{O} 2$ for an additional $2 \mathrm{~h}$. Intracellular ROS was determined by DCF-DA 
dye. Data are expressed as mean \pm SEM ( $n=3$ per group). ANOVA followed by Tukey's test: $* \star * P<0.05$ versus $H 2 O 2$ treatment; $* * P$ $<0.01$ versus $\mathrm{H} 2 \mathrm{O} 2$ treatment. $\mathrm{CC}=$ Cell control, $\mathrm{VC}=$ Vehicle control
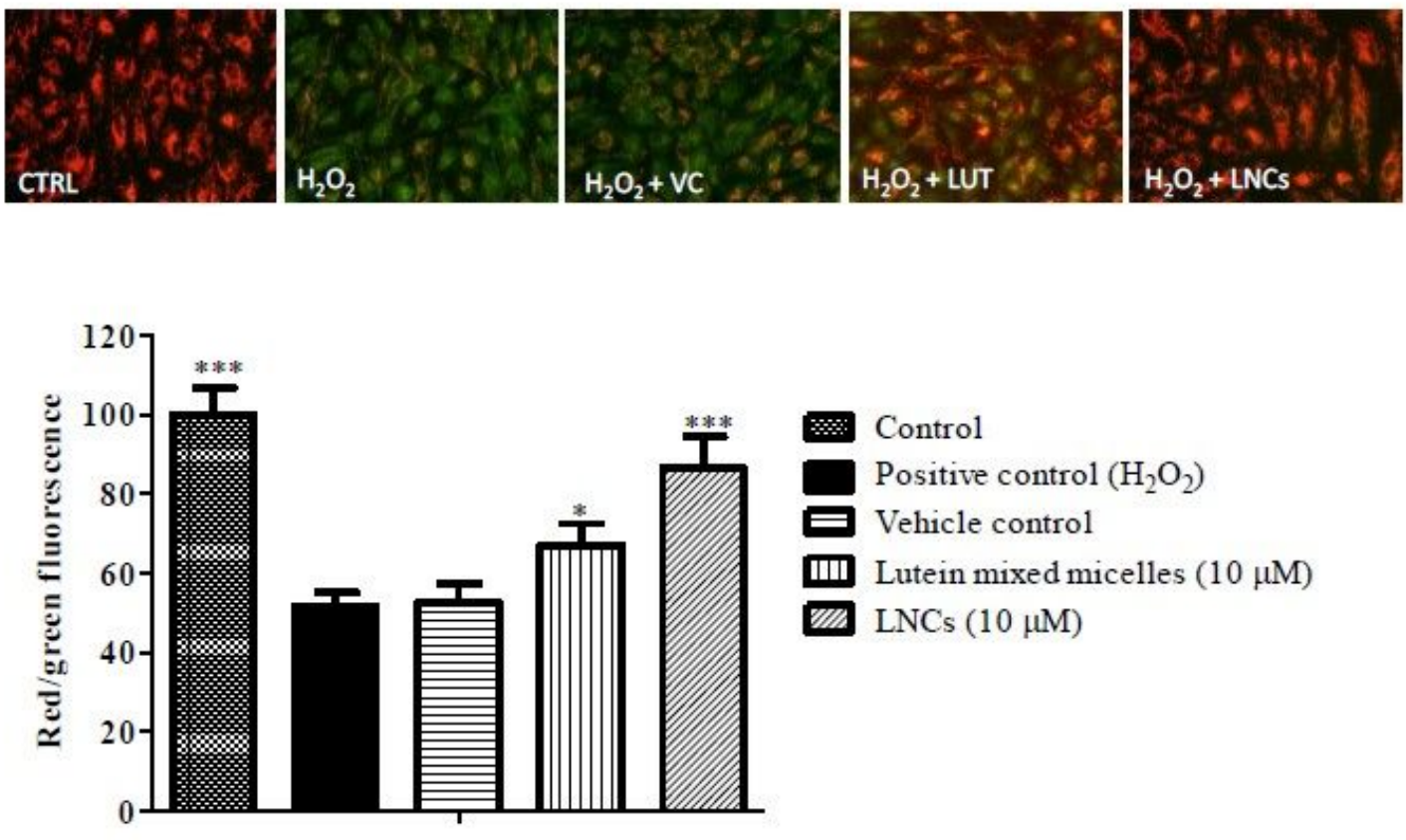

Treatment groups

\section{Figure 8}

LNCs attenuated the loss of mitochondrial membrane potential $(\mathrm{Gm})$ induced by $\mathrm{H} 2 \mathrm{O} 2$ in ARPE-19 cells after pre-treatment with $10 \mu \mathrm{M}$ lutein either as mixed micelles or LNCs for $18 \mathrm{~h}$. IIm was determined by the JC-1 assay. Data are expressed as mean \pm SEM ( $n=3$ per group). ANOVA followed by Tukey's test: ${ }^{* *} \mathrm{P}<0.05$ versus $\mathrm{H} 2 \mathrm{O} 2$ treatment; $* * \mathrm{P}<0.01$ versus $\mathrm{H} 2 \mathrm{O} 2$ treatment 1 versus $\mathrm{H} 2 \mathrm{O} 2$ treatment

\section{Supplementary Files}

This is a list of supplementary files associated with this preprint. Click to download.

- Supplementrydatafinal.docx 